Citation: Nguyen, K.A. Zhang, H. and Stewart, R.A. (2013) Development of an intelligent model to categorise residential water end use events, Journal of Hydro-environment Research, Available online 15 March 2013, ISSN 15706443, http://dx.doi.org/10.1016/j.jher.2013.02.004.

\title{
DEVELOPMENT OF AN INTELLIGENT MODEL TO CATEGORISE RESIDENTIAL WATER END USE EVENTS
}

\begin{abstract}
The aim of this study was to disaggregate water flow data collected from high resolution smart water meters into different water end use categories. The data was obtained from a sample of 252 residential dwellings located within South East Queensland (SEQ), Australia. An integrated approach was used, combining high resolution water meters, remote data transfer loggers, household water appliance audits and a self-reported household water use diary. Disaggregating water flow traces into a registry of end use events (e.g. shower, clothes washer, etc.) is predominately a complex pattern matching problem, which requires a comparison between presented patterns and those contained with a large registry of categorised end use events. Water flow data collected directly from water meters includes both single (e.g. shower event occurring alone) and combined events (i.e. an event which comprises of several overlapped single events). To identify these former mentioned single events, a hybrid combination of the Hidden Markov Model (HMM) and the Dynamic Time Warping Algorithm (DTW) provided the most feasible and accurate approach available. Additional end use event physical context algorithms have been developed to aid accurate end use event categorisation. This paper firstly presents a thorough discussion on the single water end use event analysis process developed and its internal validation with a testing set. This is followed by the application of the developed approach on three independent households to examine its degree of accuracy in disaggregating two weeks of residential flow data into a repository of residential water end use events. Future stages of algorithm development and testing is discussed in the final section.
\end{abstract}

Key words: water end use event, water micro-component, residential water flow trace disaggregation, hidden markov model, dynamic time warping algorithm, water demand management 


\section{Introduction}

After decades of inadequate metering of water use, organisations have come to the realisation that it is almost impossible to evaluate the effectiveness of residential water demand management schemes without accurate and appropriate measurement of actual water consumption at an end use or micro-component level. This desire to better monitor and analyse water consumption has led to the conceptualisation of a Knowledge Management System (KMS) which is able to collect real-time water consumption data through a smart water metering system, transfer and store the data into a knowledge repository, analyse and disaggregate data into a registry of end use events, and produce a wide range of reports which can be accessed on-line by a broad range of users (e.g. consumers, water utilities, government organisations, etc.) (Stewart et al., 2010).

Water end use data registries enable much deeper understanding on the determinants of residential urban water demand. Recently, there have been a numbers of reported studies that have utilised water end use data registries for a range of statistical modelling and decisionmaking purposes. These studies explored the determinants of shower end use consumption (Makki et al., 2011), influence of residential appliance stock efficiency on end use consumption (Beal et al., 2011a, 2011b; Willis et al., 2011a), impact of visual display monitors on shower end use consumption (Willis et al., 2010a; Stewart et al., 2011), influence of water conservation attitudes on discretionary water end use consumption (Willis et al., 2011b), and recycled water end uses in residential households (Willis et al, 2011c). Water end use studies such as these demonstrate the benefits of having available such data, and how it can be utilised to better inform urban water practices and policy going forward. However, the findings reported in these research papers were made possible through resource intensive flow trace analysis tasks in order to categorise water end use events; such an approach is not economically viable for large scale samples (i.e. citywide end use dataset).

Before such an information system can be realised and the benefits of citywide end use data registries yielded, improved approaches for disaggregating high resolution water consumption data into end use events is required. Therefore, the key enabler for this KMS is the development of pattern matching algorithms which are able to automatically categorise collected flow trace data points received from wireless data loggers into particular water enduse categories. To tackle similar complex problems, such as hand writing segmentation and recognition, speech recognition, fingerprint recognition, surface water level and seabed liquefaction predictions (Sannasiraj et al., 2004; Zhang et al., 2007), many powerful pattern 
detection tools have been established and widely applied, including Artificial Neural Network (ANN) (Moon et al., 2009), Dynamic Time Warping (DTW) (Nguyen et al., 2011) algorithm and the Hidden Markov Model (HMM) (Cho et al., 1995). However, all these methods are data driven that require training datasets in the case of ANN and HMM models or reference datasets for the DTW method. To facilitate this study, over 7000 days worth of 5 second interval flow trace data was collected from 252 homes within South East Queensland (SEQ), Australia. This flow trace data was manually disaggregated into nine different water use patterns, including shower, faucet (tap), dishwasher, clothes washer, full-flush toilet, halfflush toilet, bathtub, irrigation and leak. Utilising this extensive training set and through trialling many of the above mentioned analytical techniques (i.e. ANN, HMM and DTW), it was revealed that a hybrid approach using a combination of the Hidden Markov Model (HMM) and Dynamic Time Warping Algorithm (DTW) is the most suitable for solving this type of pattern matching problem.

A comprehensive methodology is presented herein to illustrate the identification process for all of the single event category's disaggregation from the collected flow trace data. To demonstrate the entire model design and verification process for single events, a complete clothes washer event analysis is shown. The approaches for disaggregating combined events (i.e. shower concurrent with toilet flush) are beyond the scope of this paper; however, they are briefly discussed in the context on the overall objectives of the greater study herein.

\section{$2 \quad$ Background}

\subsection{Existing water metering process}

One of the deficiencies of the existing urban water management system is the current simplistic metering process. The current water metering system does not typically provide real-time water consumption data and in cases where it does, it does not provide a sufficient level of data resolution to allow water end use event categorisation. Conventional water meters count each kilolitre of water as it passes through the meter without the ability to record when (i.e. time of day) and where the consumption takes place (e.g. washing machine, leakage, etc.). Water consumption readings are generally recorded manually on a quarterly or half yearly basis. Under most situations, a whole year's worth of water consumption data is described by only two to four data points in the water businesses billing system. No further information is available to draw upon should there be any queries. Obviously, this conventional water metering system produces limited, delayed water consumption 
information. Such a metering system is unable to provide effective support to water planning and management processes. This current metering approach is not adequate to meet the increasing level of government scrutiny on the utilisation of water resources and does not assist society at large to address the pressing water security issues associated with climate change.

\subsection{Advent of smart water metering and transition to more advanced systems}

The concept of smart metering embraces two distinct elements; meters that use new technology to capture water use information and communication systems that can capture and transmit real-time water use information. Smart water meters essentially perform three functions; they automatically and electronically capture, collect and communicate up-to-date water usage readings on a real-time (or nearly real time) basis (Neenan, 2008). Hence, a smart meter is a high frequency (e.g. 72 pulses per litre) sampling device (a data logger) that allows for the time series reading of water consumption. The information is available as an electronic signal; it can be captured, logged and processed like any other signal.

An extension to the existing architecture of the smart water metering system is an advanced integrated water management system as conceptualised here, which is designed as a powerful tool to support an integrated water conservation management system, in order to sustain water savings. The primary functions of the system include, but are not limited to, collecting real-time water consumption data through a smart water metering system, transferring and storing the data into a knowledge repository and analysing the data, and producing a wide range of reports which can be accessed on-line by a broad range of users (e.g. consumers, water utilities, government organisations, etc.).

However, the realization of such an advanced integrated water management system will only become possible when there is a robust analytical model available which can automatically and accurately disaggregate flow trace data into individual water end use event categories. The design and verification of such an analytical model is the ultimate aim of this study

\subsection{Reported water end use studies}

In recent years, a number of residential water end use studies have been completed using a range of single or mixed methods, such as household auditing, diaries, high resolution smart metering and pressure sensors, with a diverse range of per capita end use summaries. Jacobs 
(2007) and Blokker (2010) provide summaries on a good proportion of the end use models developed from stochastic techniques, contingent valuation approaches (CVA), modelling, and metered methods. The introduction of advanced technology has enabled the direct capture and classification of water end use events. Table 1 provides a summary of reported end use studies completed that have applied high resolution smart meters, data loggers or pressure sensors completed internationally in the last 15 years.

\section{[Insert table 1]}

As displayed in Table 1, from a direct measurement and water end use recognition approach which is undoubtedly the future of this type of problem, the two main approaches presently reported include using smart water meters in conjunction with a decision tree based analysis tool such as Trace Wizard or Identiflow or as more recently published, the inclusion of pressure sensors at individual appliances (i.e. HydroSense) along with a HMM based decision tool. Each approach has its own strengths and weaknesses, which were discussed in the following sections.

\subsubsection{Trace Wizard}

The presently used version of Trace Wizard is time consuming and resource intensive. The tasks required to complete an end use study are presented in Figure 1 and explained in detail in Appendix A.

\section{[Insert figure 1]}

The advantage of Trace Wizard is that it applies a simple algorithm that interprets data based on simple flow boundary conditions (e.g. minimum and maximum volume or duration range, etc.), which allows the collected data to be analysed by the tool in a considerably short period of time (i.e. excluding data preparation process). However, while the initial analysis is rapidly completed, to achieve high levels of accuracy an experienced analyst needs to review recognised events and change them where they believe that the tool is poorly classifying them. Due to this human resource requirement the overall process is extremely time and resource intensive, and greatly relies on the flow trace analyst's experience in understanding flow signatures. Moreover, Trace Wizard is only able to analyse two simultaneous water events (Trace Wizard, 2003); therefore, the prediction accuracy would be reduced where there are a number of events occurring concurrently. 


\subsubsection{Identiflow}

In 2001, WRc, a research organisation based in United Kingdom, introduced Identiflow as a cost effective program for measuring the component of domestic water consumption. Similar to Trace Wizard, the technique involved the capture of high resolution flow data and use software incorporating a decision tree algorithm to deconstruct a flow trace data series into constituent water end uses.

Identiflow achieved $74.8 \%$ accuracy in terms of the correctly classified volume when tested on 3870 events, which is relatively high compared to Trace Wizard. However, as this software was based on the analysis of fixed physical features of various water-using devices (e.g. volume, flow rate or duration, etc.) to make different decisions for categorisation, final classification accuracy is not always guaranteed and greatly dependent on the existing types of water devices. By applying this approach, two completely different water events could be placed into the same category if they have similar physical characteristics. Another disadvantage relates to its poor ability to identify modern appliance stock, for example, a washing machine manufactured in 2001 when the study was conducted could have a much different operation system, and thus flow rate and volume per wash, compared to new one produced in 2012, or a new toilet model would have a different cistern volume compared to the older one, which has a profound effect on the final recognition accuracy of Identiflow .

\subsubsection{HydroSense}

Froehlich et al. $(2009 ; 2011)$ presented a longitudinal study of pressure sensing to infer realworld water usage events in the home using a probabilistic-based classification approach. The validation showed that with a single pressure sensor, the probabilistic algorithm can classify real-world water usage at the fixture level with $90 \%$ accuracy and at the fixture category level with $96 \%$ accuracy. With two pressure sensors, these accuracies increase to $94 \%$ and $98 \%$.

This end use study approach resulted in a relatively high accuracy due to the employment of sophisticated pattern recognition algorithms. However, the main a shortcoming of the approach relates to its requirement for a number of pressure sensors to be attached to water devices inside households in order to accurately identify end use events using the HydroSense system. There may also be extensive calibration required for new homes that have different plumbing configurations to those studied (e.g. polymer pipe instead of copper). Aesthetics is another issue since the sensors are highly visible to the homeowner. These aspects potentially 
increase the cost and reduce the feasibility of widespread implementation of this approach making it more difficult to commercially apply on a citywide scale.

\subsubsection{Summary assessment and persuasion for new model development}

In summary, the ideal approach that is most amenable to citywide application is installing smart water meters at the property boundary in conjunction with intelligent end use pattern recognition algorithms either in-built into the meter software or within a processing module at the utilities data centre. This is the lowest cost and non-intrusive approach to water end use disaggregation. However, for such widespread implementation, the following summarised limitations of the existing models (i.e. Trace Wizard and Identiflow ) have to be overcome:

- inability to analyse collected data without human interaction and manual reclassification (i.e. main disadvantage);

- inability to accurately distinguish different end use categories which have similar water flow characteristics (e.g. shower, bathtub and irrigation);

- inability to classify an end use category that has various physical parameters depending on appliance models (e.g. dishwasher, clothes washer and toilet); and

- inability to deal with multi-layer combined events (i.e. cannot handle three or more concurrent events).

These shortcomings have motivated the development of an automatic flow trace analysis system which can address all of the above mentioned issues. For the building of such an intelligent model, an in-depth understanding of the existing techniques applied to this type of problem was required. Table 2 provides a brief summary of methods that have been employed in previous water end use and pattern recognition studies worldwide in the last 15 years. A rating of each technique (i.e. 1 star $(*)=$ poor; $* *=$ below average; $* * *=$ average; $* * * *=$ good; and $* * * * *=$ excellent) has also been made regarding their processing time efficiency, classification accuracy, self-learning potential and an overall applicability rating for each technique to the herein examined water end use pattern recognition process.

\section{[Insert table 2]}

The ratings shown in Table 2 have been achieved through an intensive literature review and actual application of each technique to the present study. It was found that the decision tree procedure is the most time efficient technique since it can make recognition decisions 
quickly; however, its overall applicability to end use recognition problems was rated as only "average" due to its average accuracy and its poor ability to incorporate self-learning functionality. ANN is another technique that has been widely applied to most pattern recognition problems such as hand writing, speech or signature. This technique works effectively if sufficient data is provided for training; nevertheless, the only available characteristics of one water event recorded from data logger only comprises of volume, duration, maximum flow rate and most frequent flow rate, which are not enough for the model to produce a reliable output. DTW is also a popular technique, but its application to the field of flow trace analysis was not preferred due to long processing time and average accuracy. The last technique applied in the field of pattern matching in the last 15 years is the Hidden Markov Model, which is very powerful in analysing patterns whose variations follow certain trends. It is this characteristic which makes HMM suitable to the signal collected in this study. Unlike the decision tree approach which requires the input of fixed characteristics for each pattern, or ANN that is only effective if adequate data is supplied, HMM just performs an analysis on the raw flow rate signal through the examination of flow rate change over the time. A sophisticated mathematical algorithm in HMM would be applied to reflect the true user's behaviours when consuming water, or the mechanisms of machine-based devices, such as clothes washer and dishwasher. Based on this property, no matter where and when the model is applied (i.e. in different regions at different time), if there are not significant changes in water use habits, then the proposed method is still reliable.

Based on the detailed analysis conducted above regarding the strengths and weaknesses of each mathematical technique, the study proposed a hybrid method combining HMM and DTW, whose effectiveness was assessed in comparison with the existing water flow trace analysis models as presented in Table 3. It should be noted that although DTW has a relatively higher processing time, it was still considered an appropriate technique, as the number of unclassified events required for the analysis using this technique is very small compared to the overall collected data (i.e. most of unclassified events will be initially classified by HMM, and DTW is then applied to find missing clotheswasher and dishwasher events). Moreover, the ultimate aim of the present study is to achieve the most accurate flow trace analysis model; therefore, the combination of HMM and DTW is highly recommended.

\section{[Insert table 3]}




\section{$3 \quad$ Intelligent model to categorize water end use}

\subsection{Need for understanding collected data}

To facilitate the building of such an advanced water management program, it is necessary to be able to automatically disaggregate water flow trace data into end use events. Figure 2 and 3 show examples of clothes washer and dishwasher end use patterns. These figures illustrate that most flow events have similar typologies and, therefore have strong potential to be classified using existing pattern matching techniques such as Artificial Neural Network (ANN), Dynamic Time Warping algorithm (DTW), and Hidden Markov Model (HMM). Moreover, other event probability functions can be applied to make decisions on end use categorization (e.g. higher probability for certain end use event at certain time of day). The combined application of these pattern matching and event probability functions can enable the accurate determination of residential end use events. Achievement of such an automated approach will undoubtedly be of use to the urban water industry.

\section{[Insert figure 2]}

\section{[Insert figure 3]}

\subsection{Dynamic time warping algorithm}

Dynamic time warping algorithm is one of the most popular methods in measuring the similarity between two time series of different length. In general, this task is performed by finding optimal alignment between two series with some certain restrictions. The sequences are extended or shortened in the time dimension to determine a measure of their similarity independent of certain non-linear variations in the time dimension (Gollmer \& Posten, 1996).

The goal of DTW is to find a mapping path which has the minimal mapping distance. The procedure and constraints of the DTW algorithm are summarised as:

(i) Given two vectors $\mathbf{p}=\left(\mathrm{p}_{1}, \mathrm{p}_{2}, \ldots \mathrm{p}_{\mathrm{i}}, \ldots \mathrm{p}_{\mathrm{m}}\right)$ and $\mathbf{q}=\left(\mathrm{q}_{1}, \mathrm{q}_{2}, \ldots \mathrm{q}_{\mathrm{j}}, \ldots, \mathrm{q}_{\mathrm{n}}\right)$ of length $\mathrm{m}$ and $\mathrm{n}$ respectively as in Figure 4 . The boundary condition is that the two end pairs of the vectors are matched together, i.e. $\left(p_{1}, q_{1}\right),\left(p_{m}, q_{n}\right)$.

(ii) Define $d(i, j)=\left|p_{i}-q_{j}\right|$, with $(i, j)$ is a given node in the mapping path, the possible fan-in nodes are restricted to $(i-1, j),(i, j-1),(i-1, j-1)$. This local 
constraint guarantees that the mapping path is monotonically non-decreasing in its first and second arguments (Figure 5). Moreover, for any given element, it should be able to find at least one corresponding element, and vice versa.

(iii)Define $D(i, j)$ as the accumulated DTW distance between points of $\mathbf{p}\left(p_{1}\right.$ to $\left.p_{i}\right)$ and points of $\mathbf{q}\left(\mathrm{q}_{1}\right.$ to $\left.\mathrm{q}_{\mathrm{j}}\right)$, where $(1 \leq \mathrm{i} \leq \mathrm{m})$ and $(1 \leq \mathrm{j} \leq \mathrm{n})$ and $\mathrm{D}(\mathrm{i}, \mathrm{j})=\mathrm{d}(\mathrm{i}, \mathrm{j})+$ $\min \{D(i-1, j), D(i-1, j-1), D(i, j-1)\}$, with initial condition $D(1,1)=$ $\mathrm{d}(1,1)$.

(iv) Therefore, the final accumulated DTW distance between $\mathbf{p}$ and $\mathbf{q}$ is $\mathrm{D}(\mathrm{m}, \mathrm{n})$.

\section{[Insert figure 4]}

\section{[Insert figure 5]}

In general, DTW is an algorithm to find an optimal match between two given sequences (e.g. time series) with certain restrictions. The sequences are "warped" non-linearly in the time dimension to determine a measure of their similarity independent of certain non-linear variations in the time dimension (WorldLingo, 2003). This sequence alignment method is often used in the context of HMM.

DTW plays an important role in this study as it was applied to help select a set of prototypes to represent each category of water end use patterns for network training; and during the disaggregation process, DTW is also employed to find clothes washer and dishwasher events which were missed by other classifiers.

\subsection{Hidden Markov Model}

An HMM is a stochastic finite state automation defined by the parameter $\lambda=(\pi, a, b)$, where $\pi$ is an initial state probability, $a$ is state transition probability and $b$ is observation probability, defined by a finite multivariate Gaussian mixture. Given an observed sequence $\mathbf{O}=\left(o_{1}, o_{2}, \ldots o_{t}, \ldots, o_{T}\right)$, a HMM model can be used to compute the probability of $\mathbf{0}$, denoted as $\mathrm{P}(\mathbf{O} \mid \lambda)$ and to find the corresponding state sequence that maximises the probability of $\mathbf{0}$, denoted as $\mathrm{P}(\mathrm{Q} \mid \mathbf{O}, \lambda)$. The overall process for the establishment of a HMM model is presented in Appendix B. Figure 6 illustrates a typical left-right HMM model for an observation vector $\mathbf{O}=\left(o_{1}, o_{2}, o_{3}, o_{4}, o_{5}\right)$. 


\section{[Insert figure 6]}

HMM is one of the most popular techniques in the field of hand writing and speech recognition. Chien and Wang (1997) presented an adaptation method of speech hidden Markov models for telephone speech recognition while Cho et al. (1995) applied HMM in the problem of modelling and recognising cursive words.

In the present study, HMM is utilised as the main classifier to disaggregate the majority of single events from the water flow trace data, and to help strip out all of the combined events for further analysis.

\section{$4 \quad$ Model development method}

\subsection{Collected data}

\subsubsection{Research regions}

Data utilised for the development of the model was sourced from 252 residential households fitted with a smart meter and data logger and located in the urban south east corner of the State of Queensland, Australia. These households were consenting participants in the recently completed South-east Queensland Residential End Use Study (SEQREUS) funded by the Queensland State Government (Beal and Stewart, 2012). Three separate water end use analysis reads occurred during the study. The first read was conducted in winter 2010 from $14^{\text {th }}$ June to the $28^{\text {th }}$ June. The second read was taken in the summer $2010-11$ between $1^{\text {st }}$ December 2010 and $21^{\text {st }}$ February 2011. The final two week period of analysis occurred in winter 2011 from the $1^{\text {st }}$ June to the $15^{\text {th }}$ June. It was important to obtain a dataset for this study that included the entire spectrum of events across seasonal periods (i.e. irrigation).

\subsubsection{Characteristics of participating households}

Some general characteristics (i.e. household size and makeup, income, education level, etc.) of the participating households within each region are shown in Table 4. The average number of people per household was relatively consistent across all regions for all three measurement periods, with the Sunshine Coast having the lowest average occupancy of 2.5 people per household, and the Gold Coast region having the highest average of 2.9 occupants. The percentage of households occupied by two or less people was greater in the Sunshine Coast (average of $56 \%$ ) and Gold Coast (49\%) compared to the generally larger households in 
Ipswich (53\%) and Brisbane (43\%). These percentages reflect the older demographic of the Sunshine Coast and Gold Coast regions which was also typified by the older age of children for these regions (Table 5). The descriptive statistics for the study sample are comparable to those of the wider SEQ region as published in the Australian Bureau of Statistics (ABS). The database taken from the SEQREUS was considered representative by the flow trace analysis pattern recognition team (Beal et al, 2011b)

\section{[Insert table 4]}

\subsubsection{Collected unprocessed flow dataset utilised for study}

As mentioned prior, CSV files containing $0.014 \mathrm{~L} /$ pulse water consumption data for every five second logging interval for each sample household was collected. To enable the application of HMM, water flow data collected was initially processed and manually broken down into nine different water end use categories with the number of samples shown in the second column of Table 5 using Trace Wizard (i.e. the overall process is presented in Appendix B). The database was then apportioned into a training (80\%) and testing (20\%) data set. This database was utilised for model development as described below.

\section{[Insert table 5]}

\subsection{Intelligent models to categorise water end uses}

With the availability of training data, the process of disaggregating water end use events from the raw data could be completed. Figure 7 provides an overview of the key starting decision point for the HMM algorithm, namely, whether the flow data event detected is a single event (i.e. solid line in Figure 7) or combined event (dotted line in Figure 7). As mentioned prior, single events are those which occur in isolation (e.g. toilet flush) while combined events have simultaneous occurrences of single events (e.g. shower occurring while someone is using a tap) and are therefore more challenging to disaggregate. Readers should note that this paper is focused on single event categorisation from the flow data which makes up the large majority of end use events. Stripping apart and categorising combined events are the focus of subsequent research discussed later.

\section{[Insert figure 7]}

Within the present study, a detailed analysis of single events was performed to explain all employed techniques, the reason why those techniques were utilised at different steps, as well 
as their limitations. The flow chart shown in Figure 8 illustrates the single end use event analysis process, which is the aim of this paper.

Low-flow rate leak event pulses recorded by the smart water meter (i.e. isolated 0.0139L events) are evident in a large proportion of households. These events are initially extracted from the flow trace data set and classified in the 'leak' end use category. The remaining flow data would then be analysed using HMM to classify all water end use categories. These water end uses usually belong to two broader groups: (1) depends heavily on a water user's behaviours, such as tap, bathtub, irrigation, shower and toilet; and (2) works under a pre-set mechanical process, such as clothes washer and dishwasher. It should be noted that for the purpose of this study, the end use category 'toilet' was classified into a user's behaviour group. This goes against historical conventions which indicate that toilets are mechanised devises with fixed functions (i.e. full and half flush). However, during this study the research team realised quickly that many modern toilets allow the user to select the amount of water to flush by holding down he flush button for a desired time period thereby creating a range of flush volumes for certain households. Therefore, in order that the developed analysis tool could accurately determine both the predictable mechanised toilet flushes as well as the fluctuating user defined ones, this end use category was assigned to the user behaviour group.

The application of the HMM method resulted in the categorisation of water flow data into individual end use events associated with seven end use categories (i.e. shower, clothes washer, toilet, etc.). A proportion of data was classified into another category titled inconclusive events, as they did not distinctly fit within a particular end use category. For the inconclusive event category, the DTW algorithm was firstly applied in order to determine clothes washer and dishwasher events, as these end uses often have similar repeating mechanical wash cycles that are related to others occurring within a short 1-2 hour time period. Event time-of-day probability functions (i.e. probability of a certain event occurring at a certain time of day) combined with the HMM method was also applied to classify inconclusive end use events. The process outlined in Figure 8 resulted in the classification of the training data into a repository of water end use events. A detailed discussion on the water flow trace data disaggregation process is outlined below.

\section{[Insert figure 8]}




\subsubsection{Low flow-rate leak identification}

For typical low-flow leak events which usually occur after a toilet flush or when the tap fixture is not shut tightly (i.e. slow dripping tap), the minimum registered flow rate of the smart water meter (i.e. 1 pulse equating to $0.0139 \mathrm{~L}$ occurring in 5 second recording interval equating to $0.167 \mathrm{~L} / \mathrm{min}$ flow rate) is evident. Therefore, detecting these single pulse events is relatively simple and they can be categorised into the leak end use category as a first step.

\subsubsection{HMM classification}

The three most basic parameters which constitute a hidden Markov model $(\lambda)$ are the initial state probability, state transition probability and observation probability (Camastra \& Vinciarelli, 2008). To determine these three values, the number of state should be provided. In the present study, state is defined as the number of period occurring in each water end use event. For a very basic water end use event, there could be three states, which correspond to the event starting, constant flow rate and finishing. Each state will comprise a number of data points related to that particular water flow sequence in a particular time period. However, a HMM with only three states would not be effective in recognising typical water end use events that fluctuate significantly. For example, simple three state HMM analysis would not be suitable for an event which is about to finish but the water user suddenly turns it on again or for multiple overlapped events where the finishing period of one event occurs concurrently with the starting of others, etc. Therefore, residential household water end use events modelled in this study should be split into many smaller periods (i.e. state) so that their whole process transition could be fully examined. In the context of this study, the number of state which will result in the highest recognition accuracy would be selected using an iterative method.

In total there are eight different residential water end use categories typically reported in studies and applied for this study, namely, shower, tap, dishwasher, clothes washer, toilet, bathtub, irrigation and leak. To recognise these water patterns from the water flow dataset, at least eight HMM models should be developed, one for each category. As mentioned prior, flow data also includes combined events where water end use events are occurring simultaneously (Figure 9). This category cannot be handled directly by these existing HMM. A further HMM using all combined events in the dataset can be applied in order to strip out these complicated interrelated events from the flow data. For the purpose of this study the combined events are removed from the flow dataset to enable all single events to be 
classified; solving the combined multi-event disaggregation problem into water end use events is the subject of future research.

\section{[Insert figure 9]}

In the present study, the number of state is tested from 1 to 400 , and it was found that the HMM model established using 100 states and trained at 100 iteration yields the highest recognition accuracy. The measured water flow sequence is defined as $\mathbf{0}=\left(o_{1}\right.$, $\left.o_{2}, \ldots o_{t}, \ldots, o_{T}\right)$, where $t$ is the observation time index and $T$ is the total number of flow observations; a state vector is defined as $\mathbf{q}=(1,2,3 \ldots i, \ldots, N)$, where $i$ is the state at index $i$ and $N$ is the maximum or the last state; the initial state probability is $\pi_{i}$; the state transition probability is $a_{i j}$, and the observation probability $b_{j}\left(o_{k}\right)$, where $i$ and $j$ are the state indices. Training algorithms are summarised and presented in Appendix B.

By applying the above training algorithms to the water flow datasets collected from the household smart water meters, nine different water end use event categories were achieved, including shower, tap, dishwasher, clothes washer, toilet, bathtub, irrigation, leak and combined events. The first eight end use categorises are the focus of this study, while the last combined event category will be solved in future research.

\subsubsection{Single event analysis}

Applying HMM alone for end use classification did not achieve a satisfactory level of pattern matching accuracy needed for this problem (see Table 9). To improve prediction accuracy, a number of physical characteristics for end use event category were established from the extensive available dataset, such as those following:

- Most collected shower events (87\%) had a volume of greater than 7 litres.

- The duration of a bathtub event is at least 4 minutes (91\%).

- The volume of toilet events for a particular home should be within a certain range (e.g. 3 to 8 litres) since a toilet cistern volume is fixed.

- The flow rate and duration of dishwasher and clothes washer events for a particular home should be within a certain range because these appliances have a pre-set series of wash functions.

Based on these physical characteristics, the above described HMM analysis process was then refined to include the following steps: 
- Calculate the volume of events which were classified as shower by HMM. Any shower event which had a volume of less than 7 litres would be removed and placed in an inconclusive event set for future analysis.

- Calculate the volume of events which were classified as toilet using the HMM technique. There are usually two typical volume ranges for toilet events in a particular home corresponding to both half-flush and full-flush toilet events. The first toilet event refinement task was to determine the two most frequent volumes of these two event sub-classifications, which were titled 'full toilet volume' ( $\left.\mathrm{V}_{\text {toilet_full }}\right)$ and 'half toilet volume' $\left(V_{\text {toilet_half }}\right)$. Any event whose volume is out of the range of $V_{\text {toilet_full }}+/-0.5$ litres or $V_{\text {toilet_half }}+/-0.5$ (litres) would then be removed and put in the inconclusive event dataset for further analysis.

- Determine the duration of all events which were recognised as bathtub through HMM applied alone. Any bathtub event which had duration of less than 4 minutes would be removed and put in an inconclusive event dataset for later analysis.

- Determine the flow rate of all events which were recognised as dishwasher and clothes washer through the HMM process. Determine the most frequent flow rate for the dishwasher and clothes washer event category, which were titled 'typical dishwasher flow rate' ( $\left.q_{\text {typical_dishwasher }}\right)$ and 'typical clothes washer flow rate' $\left(q_{\text {typical_clotheswasher }}\right)$, respectively. Any dishwasher event or clothes washer event whose flow rate is out of the range of $q_{\text {typical_dishwasher }}+/-1.5$ (litre/min) or $q_{\text {typical_clotheswasher }}$ +/- 1.5 (litre/min) would be then removed and put in the inconclusive event set for further analysis. To illustrate this case, Figure 10 illustrates a set of events which were classified as dishwasher using the HMM method applied alone. In the figure, there are about twelve events which do not likely belong to this end use classification because they have much different flow rates when compared to the others; such events need to be reclassified.

\section{[Insert figure 10]}

\subsubsection{Searching of dishwasher and clothes washer events missed by HMM}

Dishwasher and clothes washer are two special water end use categories which have regular cycles and have clearly defined consumption patterns. Figure 11 shows a typical clothes washer operation which comprises of 5 defined wash cycles. This section discusses the developed method used to search for missing clothes washer and dishwasher events that were 
assigned to the inconclusive dataset during the HMM preliminary analysis process. This searching process is performed using the Dynamic Time Warping (DTW) algorithm, with the reference set to be all clothes washer or dishwasher events achieved from the refinement process, and the testing set to be events from the inconclusive data set. When searching for these mechanistic events, if any event in the inconclusive data set is determined to be similar to an event in the clothes washer or dishwasher set in terms of DTW distance, then it would be stripped out and classified as clothes washer or dishwasher. DTW was employed because it is one of the most effective methods to search for patterns existing in series (e.g. one clothes washer cycle within defined timeframe from next) which also have clearly defined patterns.

\section{[Insert figure 11]}

However, this searching process can be time consuming. In order to reduce analysis time without reducing pattern matching accuracy, a prototype reference set was created and applied for the searching activity. Prior research by the authors (Nguyen et al., 2011) outlines the algorithm for prototype selection and its application methodology. In the context of this study, the number of reference prototype selected for clothes washer and dishwasher event pattern matching purposes was one quarter of the original dataset. The completion of this analysis step resulted in the large majority of previously inconclusive clothes washer and dishwasher events to be categorised appropriately.

\subsubsection{Classification of the remaining events from inconclusive category}

Once all missing clothes washer and dishwasher samples have been stripped out of the inconclusive data set, the remaining tap, toilet, irrigation, shower and bathtub events in this dataset were determined. To achieve an end use category determination for the remaining events in the inconclusive category, event time of day probability function was applied. This probability function was determined from the existing water end use database and a summary of event likelihood values in hourly intervals is detailed in Table 11.

The table shows that, for example, the probability of finding a shower event between $12 \mathrm{am}$ and $1 \mathrm{am}$ is $0.39 \%$, finding a toilet event between 1 am and 2 am is $1.11 \%$, or finding an irrigation event between 12 am and 3 am is $0 \%$. From this table, it can be seen that there is more likelihood of a toilet event between $11 \mathrm{pm}$ to 3 am than any other event, which depicts a typical households' water use pattern. By combining the probability values given in Table 6 
with those achieved using HMM, an aggregate likelihood value was determined thereby enabling the determination of the remaining inconclusive end use events into their likely end use category. This analytical process is described through an illustrative example.

For an event that was extracted from the inconclusive data set, which occurred at 2:34:12 am, the HMM probability of this event being assigned to each end use category is detailed in Table 6. From HMM applied alone, this event was most closely aligned with a dishwasher event classification, but not with sufficiently high enough probability to justify a direct assignment.

\section{[Insert table 6]}

By multiplying the HMM probability values (Table 6) with those determined from the event time of day probability distribution (i.e. 2am to 3am in Table 11), an aggregate probability for the relevant end use event categories was determined (see Table 7).

\section{[Insert table 7]}

Table 7 shows that the previously listed inconclusive event could now be appropriately classified as a toilet event. By carrying out this process with all uncertain events in the inconclusive dataset, all single events would then be matched correctly.

\section{Modelling results and discussion}

\subsection{Verification process against existing available dataset}

As mentioned in section $4.1 .3,20 \%$ of the database was reserved for verifying the proposed training algorithm. The outcomes of model testing are detailed in Table 8.

\section{[Insert table 8]}

Table 8 shows the testing accuracy of the reserved data using the HMM method applied alone. Within this verification process, HMM models for the eight different water end uses as listed above were employed to pattern match samples in the testing data set. The testing accuracy was estimated both in terms of number and respective volume of events. As can be seen from Table 8, the developed HMM models were quite good for dishwasher, clothes washer, full-flush toilet and half-flush toilet pattern recognition. The testing accuracy for 
these event categories, in terms of the number of events, is greater than $80 \%$ of the validated testing samples. The higher prediction accuracy for these categories is due to them being largely pre-set mechanical processes that are less influenced by human behaviours and thus having less variability. However, there are instances where there is potential for lower accuracy for dishwasher and clothes washer event pattern recognition where the household uses a wide variety of appliance settings in a particular analysis period. Using a large number of different appliance settings results in a much wider variety of wash patterns with some having characteristics similar with other end use event categories, creating more likelihood of misclassification when applying the proposed algorithm.

Toilet is another category which can be well recognised by HMM as it has a fairly consistent flow rate pattern and distinct volume range. It is known that most toilet cisterns have a fixed volume for both full and half flush toilet events, and a consistent refilling duration. It is these two characteristics which make the toilet event visible to the HMM classifier. However, the recognition problem becomes more challenging when dealing with toilets that exhibit leakage, which is a relatively common issue with old toilets. In this case, the typical pattern of toilet events has been distorted due to the presence of an associated leak event, which may confuse the classifier, and as a result, the matching accuracy would decrease. Another difficultly with toilet event classification is that there are some new models that allow the user to control the volume of water that is released for that particular flush.

With the other water end use categories, the pattern matching accuracy in terms of number of events is lower than $75 \%$, such as $72.9 \%$ for tap, $74.5 \%$ for shower, $73.9 \%$ for irrigation and $67.3 \%$ for bathtub (Table 8). This result, though not ideal, is somewhat understandable as all of these end use categories are heavily influenced by human behaviours and thus have high variability. When analysing the existing database, it was found that there is almost no special characteristic for these types of end use. A long tap event usually has similar features to that of shower, irrigation or bathtub events. Shower and bathtub are two categories which are most often classified as the other, and short irrigation events are usually recognised as tap events. These issues can be overcome when combining HMM with other decision-making algorithms such as the event time of day probability function described previously.

Apart from the testing in terms of number of events, the accuracy was also verified based on volume. As can be seen from Table 8, recognition accuracy in terms of total volume follows the same trend as that for number of events, albeit having lower values. This prediction 
accuracy reduction implies that most of the misclassified events are long ones which have large volumes, and from the table, it can be derived that long bathtub events are sometimes considered as long showers, and vice versa, as their accuracies in terms of volume show the greatest accuracy reduction. The increase in irrigation accuracy provides hints that most misclassified irrigation events are the short ones, which usually have similar patterns to short showers or long tap events. It is understandable that toilet total volume prediction accuracy decreases because as explained above, toilet events with associated leaks are hard to be detected correctly by the classifier, and with the additional leakage, the volume of these misclassified toilet events are often large, which results in the drop in accuracy.

\subsection{Method application to independent sample of households}

To illustrate the application of the proposed method and to verify its accuracy for an independent sample of three households, a two-week sample of high resolution flow trace data was collected from these households (named Home 1, Home 2 and Home 3). For these three households, all water end use events in the logging period were recorded by residents in a diary (i.e. accurate categorised end use event repository to compare with automated classification with herein described analytical method). This verification analysis process enabled a true indication of end use classification accuracy. A clothes washer event for Home 1was selected in order to detail all the steps involved in the single end use event recognition and classification process. A discussion is then provided to discuss the key analysis issues and outcomes for all end use categories.

\subsubsection{Applying HMM for clothes washer event recognition}

Firstly, HMM was applied for the ten different water end-use categories (i.e. tap, clothes washer, dishwasher, bathtub, shower, irrigation, full-flush toilet, half-flush toilet, leak and combined events) and were trained using HMM with $80 \%$ of the available database. The following parameters were adopted for this training: 100 states; 100 iterations; and 300 possible observations. Developed HMM for each end use category were applied to the raw flow dataset obtained from Home 1. Figure 12 illustrates the registry of clothes washer events recognised using this described analytical process.

\section{[Insert figure 12]}




\subsubsection{Refining HMM recognised clothes washer events}

As can be seen in Figure 12, the most common peak flow rate for most of the clothes washer events in Home 1 was $11.2 \mathrm{~L} / \mathrm{min}$. Clothes washer events that had a peak flow rate outside of an $11.2+/-1.5 \mathrm{~L} / \mathrm{min}$ interval range were removed from this end use category and placed in the inconclusive event category. Figure 13 shows the clothes washer events (i.e. 44 events) which remained after this refinement process was completed. A similar refinement process was performed for all other end use categories and these events were placed in the inconclusive event category dataset for further analysis.

\section{[Insert figure 13]}

\subsubsection{DTW algorithm to find missing clothes washer events from inconclusive dataset}

The next step involved searching for missing clothes washer events contained in the inconclusive dataset using the DTW algorithm. The first task in this process involved the selection of a number of prototypes from the clothes washer event dataset after the refinement process for the particular home being analysed (i.e. 44 events). Applying the approach detailed in Nguyen et al. (2011), a total of 11 clothes washer events were selected as prototypes for inconclusive event dataset screening purposes (Figure 14).

\section{[Insert figure 14]}

Once clothes washer prototypes were selected, the DTW algorithm could then be applied to screen for missing wash cycles in an entire clothes washing event. The missing wash cycle search criterion for clothes washer recognition required that the relative difference between one clothes washing event in the reference set with another one in the testing set is less than $5 \%$ in terms of DTW distance. By carrying out this process, all samples in the inconclusive set which are similar to that from the clothes washer dataset would be reassigned to the clothes washer event category. In the context of this Home 1 application, no missing clothes washer event was found in the inconclusive dataset, which infers that samples shown in Figure 13 are all clothes washer events which could be extracted from the single event dataset for this home. However, there could be many other clothes washer events contained in the 
combined event category, which have not yet been recognised. The separation and recognition of single events that are contained within combined ones is the subject of future study. By comparing the output from the proposed method with information detailed in the Home 1 water consumption dairy, the accuracy of clothes washer recognition is $91.9 \%$ (Table $10)$.

\subsubsection{End use event categorisation accuracy for remaining events}

The remaining end use event categories were processed following the above described analytical method described for the clothes washer category. A summary of the testing accuracy results for the three independent homes (i.e. Home 1 to 3 ) are described below:

- Dishwasher events: similarly to clothes washer, dishwasher events operate following a series of pre-set mechanical processes, which follow a clearly defined flow pattern. Due to this flow pattern regularity, dishwasher recognition was quite robust, with $92.1 \%, 86.5 \%$ and $96.5 \%$ classification accuracy achieved for Home 1, 2 and 3, respectively.

- Tap events: Tap events are heavily influenced by human behaviours, thereby resulting in greater irregularity in flow patterns and slightly lower pattern recognition accuracy. The application and testing process indicated that tap recognition accuracy was $83.2 \%, 95.9 \%$ and $80.1 \%$ for Home 1, 2 and 3, respectively, averaging approximately $86.4 \%$ overall (Table 9 ).

- Shower events: shower event flow patterns also have a high degree of irregularity, thus making their accurate recognition difficult. The application and testing process indicated that shower recognition accuracy was $84.8 \%, 94.8 \%$ and $94.5 \%$ for Home 1, 2 and 3, respectively, averaging approximately 91.4\% overall (Table 9). Home 1 displayed lower recognition accuracy (i.e. 84.8\%) than the others due to many shower events in this home have similar patterns to that of tap and bathtub.

- Toilet events: These events are difficult to recognise due the variety of toilets available on the market with different cistern sizes and operation modes (i.e. full flush, half flush, user defined flush). Apart from the two most common types, which are full-flush and half-flush toilet, there is another which releases a user controlled volume of water for each flush. With this type of toilet, water is only flushed when the button is held, and it will stop when the button is released. Recognising this type of toilet event is more challenging for the proposed pattern matching algorithm. The 
toilet event testing accuracy for Homes 1, 2 and 3 was 78.9\%, 80\% and 90.3\%, which is slightly lower than the most other end use categories (Table 9).

- Bathtub events: A bathtub, a long shower and an irrigation event can often have similar characteristics. Bath events are often classified as showers by HMM and vice versa. Due to these issues, the recognition of bathtub events was considerably lower than the other event categories (i.e. low $70 \%$ accuracy values). To improve bathtub recognition accuracy further context data will be trialled in future model refinement stages of the research.

- Irrigation events: Irrigation events do not often occur in an individual household in a particular recording period (i.e. Home 1) and when they do occur they are often have irregular flow patterns. Due to these issues, irrigation event categorisation accuracy was the lowest of all event categories at $56.4 \%$ to $66.1 \%$, for Homes 2 and 3, respectively. Again, further context data will be a trialled in future model refinement stages of the research.

\subsubsection{Comparison between standalone HMM and method with additional processes}

HMM was selected as the basic classifier for the problem addressed in this study, however, due to the nature of the water flow data to be analysed, the technique applied alone did not adequately classify water end use events. To overcome the standalone HMM limitations, the above mentioned additional data refinement and processing steps improved recognition accuracy. The differences in end use event classification accuracy, in terms of number of events, when using HMM to test $20 \%$ of the reserved data, using only HMM on the new dataset, and using HMM in conjunction with a number of additional analysis processes on the new dataset, are presented in Table 9.

\section{[Insert Table 9]}

There appears to be no general trend in accuracy variation for each end use category when applying the standalone HMM technique on the $20 \%$ reserved data and on the three independent household datasets (Table 9). Accuracy reduced for bathtub, irrigation and toilet event recognition while a significant increase was achieved for shower. A robust trend could be seen on the remaining categories such as tap, dishwasher, and clothes washer. 
More importantly, the change in recognition accuracy with the inclusion of the additional analysis processes is of greater concern. The inclusion of the additional analysis processes resulted in a significant improvement in end use classification accuracy for all categories. For end use categories which had clearly defined patterns such as dishwasher and clothes washer, an average classification accuracy increase of $6.1 \%$ and $5.5 \%$ respectively (average of three homes) was achieved. These relative small increases in event classification accuracy is due to the fact that the standalone HMM technique is robust for classifying consistent mechanised water flow patterns that are less influenced by human behaviours

For end use categories that are more behaviourally influenced (i.e. tap, shower, toilet, bathtub and irrigation) and thus had higher flow pattern variability, there were much greater improvements in classification accuracy when the additional analysis processes were applied. An average increase of three homes of $9.7 \%$ for tap, $10.4 \%$ for shower, $8.9 \%$ for toilet, $25.1 \%$ for bathtub and $24 \%$ for irrigation was attained. This improvement in classification accuracy indicates that the additional processes applied are effective in recognising events which are not easily recognised by the standalone HMM. In summary, the testing and application verification process provides strong evidence that residential water flow data disaggregation into end use event categories, requires a range of pattern matching, probabilistic and contextual analysis processes in order to achieve a desired level of accuracy. While most event categories exhibited good classification accuracy when applying the complete model, further analysis procedures need to be implemented to improve others; this is the subject of future research along with the disaggregation and classification of combined events.

\section{Comparison between proposed method with existing flow trace analysis tool}

One of the most popular flow trace analysis tools available in the market place is Trace Wizard, which was utilised for manual end use analysis for the repository of input data provided for this automated recognition study. This software requires several inputs for the flow trace disaggregation process, including minimum and maximum values of volume, duration, peak and most frequent flow rate of each end use category. For this software package to be applied accurately for the flow trace disaggregation process, it requires a lot of information sources to aid the analyst, including: (1) diary of water use for a particular period to understand general water use behaviours; (2) household water appliance/fixture audit (i.e. 2 hours) to survey the features of water using devices (i.e. toilet flush volumes, clothes 
washer average wash, flow rate of taps, etc.); (3) descriptive information on household participants (i.e. number of adults and children, etc.); and (4) water flow signature traces for each appliance. Even with the assistance of these information sources, high recognition accuracy is only achieved when an experienced analyst spends approximately 2 hours, for a 2-week sample of flow data, to run analysis templates using this data as input, and manually checks that each end use event is being classified properly. Moreover, cross checking of the end use events from user's diary against results exported from Trace Wizard has shown that the average accuracy of this software was just approximately $72 \%$. Obviously, such a process cannot be applied on a widespread scale unless a robust automated method is developed to complete this task.

To illustrate the accuracy of Trace Wizard analysis, without extensive manual intervention by an analyst, event recognition accuracy was determined for Homes 1 through to 3 . Table 10 details the level of classification accuracy, in terms of number of events, achieved using both the existing Trace Wizard software tool and the new analytical method developed. Readers should note that the comparison is made only on the basis of single event classification (i.e. combined events have been removed from the sample).

[Insert Table 10]

Table 10 demonstrates that the developed method had high classification accuracy than Trace Wizard for the majority of water end use categories. The toilet end use category for Home 1 and Home 2, and the irrigation end use category for Home 2 were the only end uses which showed slightly better accuracy when analysed with Trace Wizard. The results show strong potential for the developed method to be further refined and improved in order to create an accurate, reliable and automated water end use disaggregation method that has commercial applications.

\section{$7 \quad$ Study implications}

The model developed in this study is the key element for the building of a Knowledge Management System (KMS) which is able to automatically categorise the flow data recorded from water meter into all end-use categories. One application of the KMS allows for 
individual consumers to log into their user-defined water consumption web page to view their daily, weekly and monthly consumption tables as well as charts on water consumption patterns for categories of water end use. Moreover, cumulative water billing can be updated daily or even hourly, and on-line alarms could be generated to indicate potential causes for excessive water use (e.g. internal leaks). This will help consumers to take corresponding water saving actions. The availability of such fine grained water end use data will enable a water utility to intervene as soon as an exception alarm is raised for end uses such as a major water leak (Britton 2008; 2009). From an operational perspective, there are significant implications of the KMS for improving current practices of infrastructure planning and management. The provision of demand and supply data from water and wastewater systems and households can assist system modelling through:

- Providing real-time diurnal pattern data of water demands at a household level which will assist with understanding required supply quantities, storage needs, excess supply available for resale or distribution, and discharge volumes; and

- Providing better predictive models on wastewater system requirements (e.g. treatment processes, estuarine, marine and river impacts, etc.) through real-time end use data related to prior knowledge on the typical waste constitute materials associated with such uses.

The data from a KMS will also provide significant insight into the development and effectiveness of water demand management strategies at the development scale.

Moreover, the application of a KMS could significantly improve on current decision making relating to the development of Water Demand Management (WDM) strategies as well as provide empirical verification on achieved water savings from already implemented programs. The application of real-time end use data, for both water authorities and consumers, will undoubtedly revolutionise the current ad-hoc approach to WDM. Some of the benefits of a KMS for enhancing current demand management functions include the following:

- The ability to monitor the effect of enforcement or restriction levels on water consumption; 
- The ability to immediately quantify the effect of targeted education programs (e.g. for particular demographics, shower time, rebate program, etc.) on their intended water end use(s);

- The capacity to establish the water savings resulting from implemented engineering applications such as efficient water appliances (e.g. washing machines, shower roses, etc.) and pressure and leakage management (Carragher et al., 2012);

- The provision of real time water consumption data provided to water users/customers resulting in an increased level of knowledge and understanding of personal water consumption and how this compares with others;

- A tool for definitive financial analysis of the cost and water saving benefits of implemented WDM programs, ultimately driving a least cost planning agenda; and

- Easy identification of leakage in households or businesses.

The KMS will allow for the instantaneous quantification of the effect of WDM strategies on water consumption. This will lead to significant improvement on the development and delivery of such measures, thus closing the loop on demand management strategies. Stewart et al. (2010) provides a detailed discussion on the benefits of smart metering and high resolution water end use data for enhanced urban water infrastructure planning and management.

\section{Conclusions and future research}

Smart water metering technology is presently available which can provide real-time high resolution water consumption data to the householder and water business. Availability of such high resolution residential water flow data allows for its disaggregation into individual water end use events, which is essential for a range of intelligent urban water management functions. While high resolution flow data can be obtained, the flow data disaggregation process is far from automated, requiring time consuming and resource intensive manual analysis, thereby making it a niche activity for water end use research studies. In an attempt to automate this end use disaggregation process and thus enhance current practices in the urban water industry, this study developed a robust hybrid analytical method employing HMM, DTW and event probability techniques. Pattern recognition algorithms (i.e. HMM) applied alone were not sufficient for accurate event categorisation due to the close similarity 
between flow events. Context data such as the event time of day probability, established from an existing available end use database, combined with event category likelihood established from HMM enabled more accurate predictions of inconclusive events.

The developed analytical method was reliable for categorising most end use categories with the exception of irrigation and bathtub. In order to significantly improve irrigation and bathtub recognition accuracy, as well as make smaller improvements to the other end use categories, further analytical processes and the application of more contextual data will be employed in future research. To achieve this, the researchers are currently seeking to build a greater repository of contextual data about each end use event category (i.e. relative frequency distributions for number, flow rate, duration, and volumes for each end use category) as well as build an optional analytical module allowing individual household calibration through the inclusion of descriptive information (i.e. number of children and adults, appliance stock information, etc.). The incorporation of these analytical steps is expected to significantly increase the level of inconclusive event pattern recognition. Another task considered for future research is to develop a technique to automatically find the most appropriate parameters for the HMM model (i.e. states, iterations and possible observations) rather than using trial and error approaches as presented in the current study. Moreover, the authors are presently working on developing a dynamic algorithm, which is able to self-learn from newly collected raw data from different independent smart meter sources, without completely relying on data registries achieved from previously collected database prototypes. This is the final goal of the current research investigation, which will enable the developed model to handle incrementally changing water flow patterns posed by the ongoing changes in water appliance technologies installed in households and shifting human behaviours.

\section{References}

Bhadeshia, H. K. D. H. 1999. Neural metworks in materials science. ISIJ International 39 (10):966-979.DOI:10.2355/isijinternational.39.966. http://www.msm.cam.ac.uk/phasetrans/abstracts/neural.review.pdf.

Baum, L. E. Petrie, T. 1966. Statistical inference for probabilistic functions of finite state Markov chains. The Annals of Mathematical Statistics 37 (6): 1554-1563. DOI:10.1214/aoms/1177699147. 
Baum, L. E. Petrie, T. Soules, G. Weiss, N. 1970. A maximization technique occurring in the statistical analysis of probabilistic functions of Markov chains. The Annals of Mathematical Statistics 41: 164. DOI:10.1214/aoms/1177697196.

Beal, C., Stewart, R.A., 2012. South East Queensland residential end use study: final report. Technical Report No. 47 for Urban Water Security Research Alliance. Griffith University and Smart Water Research Centre, January 2012.

Beal, C., Stewart, R.A., Huang, T.T., 2011a. South East Queensland residential end use study: baseline results - winter 2010.Technical Report No. 31 for Urban Water Security Research Alliance. Griffith University and Smart Water Research Centre, November 2010

Beal, C., Stewart, R.A., Huang, T.T., Rey, E., 2011b. SEQ residential end use study. Journal of the Australian Water Association 38 (1), 80-84.

Bishop, C.M. 1995. Neural Networks for Pattern Recognition, Oxford: Oxford University Press. ISBN 0-19-853849-9 or ISBN 0-19-853864-2

Blokker E, Vreeburg J, Van Dijk J., 2010. Simulating residential water demand with a stochastic end use model. Journal of Water Resources Planning and Management; 136: $19-26$.

Bouwer H., 2000. Integrated water management: emerging issues and challenges. Agricultural Water Management; 45: 217 - 228.

Britton, T., Cole, G. , Stewart, R., Wisker, D., 2008. Remote diagnosis of leakage in residential households. Water : journal of the Australian water association, 35, 89-93.

Britton, T., Stewart, R. A., O'Halloran, K., 2009. Smart metering: Providing the foundation for post meter leakage management. IWA Efficient 2009 Conference, Sydney, Australia.

Camastra, F., Vinciarelli, A. 2008. Markovian Models for Sequential Data. Machine Learning for Audio, Image and Video Analysis. Springer London.

Carragher, B. J., Stewart,R. A., Beal, C. D., 2012. Quantifying the influence of residential water appliance efficiency on average day diurnal demand patterns at an end use level: A precursor to optimise water service infrastructure planning. Elseviwe. Resources, Conservation and Recycling 62 (2012), 81-90.

Cha, S. H.; Tappert, C. C. 2009. A Genetic Algorithm for Constructing Compact Binary Decision Trees. Journal of Pattern Recognition Research 4 (1): 1-13. http://www.jprr.org/index.php/jprr/article/view/44/25. 
Chien, J.-T., Wang, H.-C. 1997. Telephone speech recognition based on Bayesian adaptation of hidden Markov models. Speech Communication, 22, 369-384.

Cho, W., Lee, S.-W., Kim, J.H., 1995. Modeling and recognition of cursive words with hidden Markov models. Pattern Recognition 28(12): 1941-1953. doi: 10.1016/00313203(95)00041-0

Da, Y., Xiurun, G. 2005. An improved PSO-based ANN with simulated annealing technique.

In T. Villmann. New Aspects in Neurocomputing: 11th European Symposium on Artificial Neural Networks. Elsevier. DOI:10.1016/j.neucom.

Deng,H.; Runger, G.; Tuv, E. 2011. Bias of importance measures for multi-valued attributes and solutions. Proceedings of the 21st International Conference on Artificial Neural Networks (ICANN). http://enpub.fulton.asu.edu/hdeng3/MultiICANN2011.pdf.

Eggers, G., Politti, E., Woo, H., Cho, K-H., Cho, H., Benjankar, R. Lee, N-J., Lee, H. 2012. Dynamic vegetation model as a tool for ecological impact assessments of dam operation. Journal of Hydro-environment Research, Special Issue on Ecohydraulics: Recent Research and Applications, 6(2), 151-161.

Froehlich, J., Larson, E., Saba, E., Campell, T., Atlas, L., Fogarty, J., Patel, S., 2011. A longitudinal study of pressure sensing to infer real-world water usage events in the home. Computer Science and Engineering. University of Washington

Froehlich, J.E., Larson, E., et al., 2009. HydroSense: infrastructure-mediated single-point sensing of whole-home water activity. In: Proc. of UbiComp 2009, Orlando, Florida, USA, pp. 235-244 .

Ghahramani, Z., Jordan, M. I. 1997. Factorial Hidden Markov Models. Machine Learning 29 (2/3): 245-273. DOI:10.1023/A:1007425814087.

Gollmer, K., Posten, C., 1996. Supervision of bioprocesses using a dynamic time warping algorithm. Control Engineering Practice 4(9): 1287-1295.

Haykin, S. 1999. Neural Networks: A Comprehensive Foundation, Prentice Hall, ISBN 0-13273350-1

Heinrich, M., Water End Use and Efficiency Project (WEEP), 2007- Final Report. BRANZ Study Report 159, Branz, Judgeford, New Zealand.

Hertz, J., Palmer, R.G., Krogh. A.S. 1990. Introduction to the theory of neural computation, Perseus Books. ISBN 0-201-51560-1

Jacobs, H. E. 2007. The first reported correlation between end-use estimates of residential water demand and measured use in South Africa. Water SA; 33(4): 549 - 558. 
Kowalski, M. and Marshallsay, D., 2005. Using measured micro-component data to model the impact of water conservation strategies on the diurnal consumption profile. Water Science and Technology:Water Supply; 5(3-4), 145-150.

Makki, A.A., Stewart, R.A., Panuwatwanich, K., Beal, C., 2011. Revealing the determinants of shower water end use consumption: enabling better targeted urban water conservation strategies, Journal of Cleaner Production, in-press, doi:10.1016/j.jclepro.2011.08.007

Mayer P, DeOreo W, Towler E, Martien L, Lewis, D., 2004. Tampa water department residential water conservation study: the impacts of high efficiency plumbing fixture retrofits in single-family homes. Aquacraft Inc. Water Engineering and Management, USA.

Mead N. Investigation of domestic end use, 2008. Honours Thesis, Faculty of Engineering \& Surveying, University of Southern Queensland, Toowoomba, Australia.

Moon, J. W., Jung, S. K., Kim, J. J., 2009. Application of Artificial Neural Network in thermal control. Eleventh International IPBSA Conference. Glasgow, Scotland, July 27-30, 2009

Muller, M., 2007. Information Retrieval for Music and Motion, Chapter 4 . Springer, ISBN 978-3-540-74047-6.

Myers, C. S., Rabiner, L. R., 1981. A comparative study of several dynamic time-warping algorithms for connected word recognition. The Bell System Technical Journal, 60, 1389-1409.

Neenan, B. A. H., R., 2008. Social benefits of smart metering investments. The electricity journal 21, 32-45.

Nguyen, K.A., Zhang, H., Stewart, R.A., 2011. Application of Dynamic Time Warping algorithm in prototype selection for the disaggregation of domestic water flow data into end use events. Proceeding of the 34th World Congress of the International Association for Hydro-Environment Engineering and Research, pp2137-2144, Brisbane, Australia, 26 June-1July, 2011.

Rabiner, L., Juang, B. 1993.Fundamentals of speech recognition. Prentice-Hall, Inc., Chapter 4.Rabiner, L. R. 1990. A tutorial on hidden Markov models and selected applications in speech recognition. Readings in speech recognition. Morgan Kaufmann Publishers Inc.

Roberts P. Yarra valley water. 2004 residential end use measurement study. Yarra Valley Water, Melbourne, Australia; 2005. 
Sannasiraj, S. A., Zhang, H., Babovic. V., Chan, E.S., 2004. Enhancing tidal prediction accuracy in a deterministic model using chaos theory, Advances in Water Resources, $27,761-772$.

Sakoe, H., Chiba, S., 1978. Dynamic programming algorithm optimization for spoken word recognition, Acoustics, Speech and Signal Processing,19 IEEE Transactions on, vol. 26, no. 1, pp. 43\{49, 1978. [Online]. Available: http://ieeexplore.ieee.org/xpls/abs all.jsp?arnumber $=1163055$

Satish, L., Gururaj, B. I. 2003. Use of hidden Markov models for partial discharge pattern classification. IEEE Transactions on Dielectrics and Electrical Insulation.

Starner, T., Pentland, A.1995. Real-Time American Sign Language Visual Recognition From Video Using Hidden Markov Models. Master's Thesis, MIT, Program in Media Arts.

Stewart, R. A., Willis, R., Giurco, D., Panuwatwanich, K., Capati, G., 2010. Web-based knowledge management system: linking smart metering to the future of urban water planning. Australian Planner, 47, 66 - 74.

Stewart, R.A., Willis, R.M., Panuwatwanich, K., Sahin, O., 2011. Showering behavioural response to alarming visual display monitors: Longitudinal mixed method study. Journal of Behaviour and Information Technology, in press, doi:10.1080/0144929X.2011.577195

Tapia, E., Intille, S.S., Larson, K., 2004. Activity Recognition in the Home Using Simple and Ubiquitous Sensors. In: Ferscha, A., Mattern, F. (eds.) PERVASIVE 2004. LNCS, vol. 3001, pp. 158-175. Springer, Heidelberg (2004)

Trace Wizard. 2003. Trace Wizard water use analysis tool. Users Manual. Aquacaft, Inc.

Willis, R.M., Stewart, R.A., Panuwatwanich, K., Jones, S., Kyriakides A., 2010a. Alarming visual display monitors affecting shower end use water and energy conservation in Australian residential households. Resources, Conservation and Recycling 54 (12), 1117-1127.

Willis, R.M., Stewart, R.A., Giurco, D.P., Talebpour, M.R., 2011a. End use water consumption in households: impact of socio-demographic factors and efficient devices, Journal of Cleaner Production, in-press, doi:10.1016/j.jclepro.2011.08.006

Willis, R.M., Stewart, R.A., Panuwatwanich, K., Williams, P.R., Hollingsworth, A.L., 2011 b. Quantifying the influence of environmental and water conservation attitudes on household end use water consumption. Journal of Environmental Management 92 (8), 1996-2009. 
Willis, R.M., Stewart, R.A., Williams, P., Hacker, C., Emmonds, S., Capati, G., 2011c. Residential potable and recycled water end uses in a dual reticulated supply system. Desalination 272 (1-3), 201-211.

WorldLingo. 2003. Dynamic time warping [Online]. Available: http://www.worldlingo.com/ma/enwiki/en/Dynamic_time_warping [Accessed 29-102010].

Yiee, H.H. and Baskin, L.S. (2011) Use of internal stent, external transanastomotic stent or no stent during pediatric pyeloplasty: A decision tree cost-effectiveness analysis, The Journal of Urology, 185(2), 673-681.

Yuan, Y.; Shaw, M. J. 1995. Induction of fuzzy decision trees. Fuzzy Sets and Systems 69 pp. 125-139

Zhang, H., Jeng, D.-S., Cha, D., Blumenstein, M., 2007. Parametric study on the Prediction of Wave-induced Liquefaction using an Artificial Neural Network Model, SI 50, Journal of Coastal Research, 374-378.

\section{APPENDICES}

\section{Appendix A: Main tasks to be completed for an end use study}

- Task 1: A detailed water appliance/fixture stock inventory audit would be conducted by a researcher for each household within the surveyed group to determine the efficiency rating of each household fixture/appliance, household general water use behaviours (e.g. bath children at night), and household descriptive statistics (e.g. family make-up). Households were also requested to complete a diary of water use events over a one week period to gain even further knowledge on their water use habits.

- Task 2: High resolution water meters (0.014 litres per pulse) and data loggers were used to record water volume data verse time (i.e. 5 or 10 seconds) for each household usually over a representative 2 -week period.

- Task 3: Analysts used completed water audits and diaries as well as sample flow trace data for each household to develop specific templates which served to pattern match water end uses based on some basic event boundary conditions, such as peak and mode flow rate, volume, duration, etc. 
- Task 4: Based on developed templates, stock survey audit, diary information and the analysts' experience, individual end uses were disaggregated and categorised using Trace Wizard.

\section{$\underline{\text { Appendix B: HMM classification training algorithms }}$}

Step 1: Assume random probabilities for initial state probability $\pi_{i}$, state transition probability $a_{i j}$, and observation probability $b_{j}\left(o_{k}\right)$ as their initial valueswith the restrictions as follows:

$\sum_{j=1}^{100} \pi_{j}=1$ : Total probabilities of starting in state $j$ at time 1 is equal to 1 . In this study, with 100 states as suggested, a random vector containing 100 values, whose sum is 1 , is selected for initial state probability $\pi_{i}$

$\sum_{j=1}^{100} a_{i j}=1$ : Total transition probability from state $\mathrm{i}$ to all other states is equal to 1 ; therefore, random matrix with 100 rows and 100 columns (100 x 100), whose sum of each row is 1 , is selected for state transition probability $a_{i j}$ (i.e. for 100 states)

$\sum_{k=1}^{300} b_{j}\left(o_{k}\right)=1$ : Total probability of having observation $o_{k}$ at state $j$ is equal to 1 . There are 300 possible observations as proposed for this study (i.e. the maximum flow rate recorded from water meter of any residential household never exceeds 300 pulses), a matrix with 100 rows and 300 columns, whose sum of each column is 1 , is randomly selected for observation probability $b_{j}\left(o_{k}\right)$

The selection of random values for the above mentioned parameters does not affect the overall model as with each event presented for training, step 2, 3 and 4 will be then carried out 100 times (i.e. 100 iterations) to ensure that the values of $\pi_{i}, a_{i j}$ and $b_{j}\left(o_{k}\right)$ will converge to a certain number for each training sample

Step 2: Using the values from step 1, determine the following parameters:

- $\alpha_{\mathrm{t}}(i)$ : the probability of flow rate $o_{1}$ through to $o_{t}$ and being in state $i$ at time $t$ $\left(q_{t}=i\right)$ given the $\operatorname{HMM}(\lambda)$

$$
\alpha_{t}(i)=P\left(o_{1} o_{2} \ldots o_{t}, q_{t}=i \mid \lambda\right)
$$


- $\beta_{t}(i)$ : the probability of flow rate $o_{t+1}$ through to $o_{T}$, given the HMM ( $\lambda$ ) and given that the model is currently in state $i$ at time $t\left(q_{t}=i\right)$

$$
\beta_{t}(i)=P\left(o_{t+1} o_{t+2} \cdots o_{T} \mid q_{t}=i, \lambda\right)
$$

- $\quad \gamma_{t}(i)$ : the probability of being in state $i$ at time $t$ given a water flow sequence $(\mathbf{O})$ and $\operatorname{HMM}(\lambda)$

$$
\gamma_{t}(i)=\frac{\alpha_{t}(i) \beta_{t}(i)}{\sum_{j=1}^{N} \alpha_{t}(j) \beta_{t}(j)}
$$

- $\quad \xi_{t}(i, j)$ : the probability of being in state $i$ at time $t$, and in state $j$ at time $t+1$, given a water flow sequence $(\mathbf{O})$ and the $\operatorname{HMM}(\lambda)$ as .

$$
\xi_{t}(i, j)=\frac{P\left(q_{t}=i, q_{t+1}=j, \mathbf{O} \mid \lambda\right)}{P(\mathbf{O} \mid \lambda)}
$$

$$
\text { where } P(\mathbf{O} \mid \lambda)=\sum_{k=1}^{N} \sum_{p=1}^{N} \alpha_{t}(k) a_{k p} b_{p}\left(o_{t+1}\right) \beta_{t+1}(p) \text {, }
$$

and $\quad P\left(q_{t}=i, q_{t+1}=j, \mathbf{O} \mid \lambda\right)=\alpha_{t}(i) a_{i j} b_{j}\left(o_{t+1}\right) \beta_{t+1}(j)$

Step 3: Calculate the following parameters for each water flow sequence ( $\mathbf{O}$ )

$\sum_{t=1}^{T} \gamma_{t}(i)$ : expected number of times in state $i$ for the water flow sequence $(\mathbf{O})$

$\sum_{i=1}^{T-1} \gamma_{t}(i)$ : expected number of transition from state $i$ for the water flow sequence $(\mathbf{O})$

$$
\sum_{t=1}^{T-1} \xi_{t}(i, j): \text { expected number of transition from state } i \text { to state } j \text { for the flow rate }
$$


sequence $(\mathbf{O})$

Step 4: With the calculated values in step 3, the probabilities values of $\pi_{i}, a_{i j}$ and $b_{j}\left(o_{k}\right)$ can be updated by performing Equations 5 - 7

$$
\bar{\pi}_{i}=\gamma_{1}(i)
$$

$$
\begin{gathered}
\bar{a}_{i j}=\frac{\sum_{t=1}^{T-1} \xi_{t}(i, j)}{\sum_{t=1}^{T-1} \gamma_{t}(i)} \\
\bar{b}_{j}\left(o_{k}\right)=\frac{\sum_{\substack{t=1 \\
\text { such that } \mathbf{o}_{t}=\mathbf{v}_{k}}}^{T} \gamma_{t}(j)}{\sum_{t=1}^{T} \gamma_{t}(j)}
\end{gathered}
$$

It should be noted that the above calculations of $\pi_{i}, a_{i j}$ and $b_{j}\left(o_{k}\right)$ will be updated for any new water flow rate sequence ( $\mathbf{O}$ ) introduced into the HMM. The overall process is completed when all samples have been introduced for training. Once the final $\operatorname{HMM}(\lambda)$ with $\pi_{i}, a_{i j}$ and $b_{j}\left(o_{k}\right)$ are available, the recognition process of new water flow sequence could be ready. Probability of a water flow sequence given a HMM can be determined using the following formula:

$$
P(\mathbf{O} \mid \lambda)=\sum_{i=1}^{N} \alpha_{T}(i)
$$

where $\alpha_{T}(i)$ is the probability of flow rate $o_{1}$ through to $o_{T}$ and being in state $i$ at time $T$, given the $\operatorname{HMM}(\lambda)$.

\section{Appendix C}


Table 1. Conducted water end use studies using smart water meter, data logger and pressure sensor (Beal and Stewart, 2012)

\begin{tabular}{|c|c|c|c|c|c|c|c|}
\hline Study & Location & $\begin{array}{l}\text { Sample } \\
\text { size (hh) }\end{array}$ & Sample regime & Dwelling type/s & Data capture & Data transfer and analysis & Reference \\
\hline $\begin{array}{l}2011 \text { - USA University of } \\
\text { Washington }\end{array}$ & Seattle, USA & 5 & 5 weeks & Mixture & Pressure sensor & $\begin{array}{l}\text { Data transferred wirelessly to } \\
\text { PC. Analysis using } \\
\text { HydroSense }\end{array}$ & Froehlich et $a l .(2011)$ \\
\hline $\begin{array}{l}2009-2011 \text { Gold Coast } \\
\text { Watersaver EUS }\end{array}$ & $\begin{array}{l}\text { Gold Coast, } \\
\text { Aust. }\end{array}$ & 252 & $\begin{array}{l}\text { Winter } 2008 \text { and } \\
\text { Summer } 2009\end{array}$ & $\begin{array}{l}\text { Single, } \\
\text { detached, dual } \\
\text { reticulation }\end{array}$ & $\begin{array}{l}\text { Actaris CT5-S meters, Aegis } \\
\text { Datacell R series loggers, } 10 \mathrm{sec} . \\
\text { int. }\end{array}$ & $\begin{array}{l}\text { Manual download to PC in- } \\
\text { situ Trace Wizard® }\end{array}$ & $\begin{array}{l}\text { Willis et al. (2010a, } \\
\text { 2011b) }\end{array}$ \\
\hline $\begin{array}{l}2008 \text {-USQ Investigation } \\
\text { of domestic water end use }\end{array}$ & $\begin{array}{l}\text { Toowoomba, } \\
\text { Aust. }\end{array}$ & 10 & $\begin{array}{l}\text { Continuous for } \\
138 \text { days }\end{array}$ & Single detached & $\begin{array}{l}\text { Actaris CT5-S meters, Monita R } \\
\text { series loggers, } 10 \text { sec. int. }\end{array}$ & $\begin{array}{l}\text { Wireless download - weekly } \\
\text { email Trace Wizard® }{ }^{\circledR}\end{array}$ & Mead (2008) \\
\hline $\begin{array}{l}2007 \text { - NZ Water End Use } \\
\text { and efficiency project }\end{array}$ & $\begin{array}{l}\text { Auckland } \\
\text { region }\end{array}$ & 51 & $\begin{array}{l}6 \text { months: across } \\
\text { summer and } \\
\text { winter }\end{array}$ & Single, detached & $\begin{array}{l}\text { Neptune disc meter, } 34.2 \text { pulses/L, } \\
\text { Branz data loggers, } 10 \mathrm{sec} \text { int. }\end{array}$ & 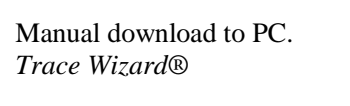 & Heinrich (2007) \\
\hline $\begin{array}{l}2005 \text { - Yarra Valley } \\
\text { Water Residential End } \\
\text { Use study }\end{array}$ & $\begin{array}{l}\text { Yarra Valley, } \\
\text { VIC, Aust. }\end{array}$ & 100 & $\begin{array}{l}2 \times 2 \text { wks summer } \\
\text { and winter }\end{array}$ & Single detached & $\begin{array}{l}\text { Actaris CT5 modified to } 72 \\
\text { pulses/L. Monatec XT logger, } 5 \mathrm{sec} \\
\text { int. }\end{array}$ & $\begin{array}{l}\text { Manual download into MS } \\
\text { Access database. Trace } \\
\text { Wizard }{ }^{\circledR}\end{array}$ & Roberts (2004) \\
\hline $\begin{array}{l}2004 \text { - Tampa Water } \\
\text { Department Residential } \\
\text { Water Conservation Study }\end{array}$ & Florida, USA & 26 & $\begin{array}{l}2 \mathrm{wk} \text { baseline data } \\
+2 \times 2 \mathrm{wk} \text { data } \\
\text { post retrofit }\end{array}$ & $\begin{array}{l}\text { High end users } \\
(230 \mathrm{~L} / \mathrm{p} / \mathrm{d})\end{array}$ & $\begin{array}{l}\text { Trident T- } 10 \text { or Badger } 25 \text { meters, } \\
\text { Meter-Master loggers, }\end{array}$ & $\begin{array}{l}\text { Downloaded to PC and } \\
\text { Trace Wizard }{ }^{\circledR}\end{array}$ & Mayer et al. (2004) \\
\hline $\begin{array}{l}2003 \text { - Smart metering } \\
\text { project in UK }\end{array}$ & $\begin{array}{l}\text { Across } 10 \mathrm{UK} \\
\text { Water utilities }\end{array}$ & 250 & On going & Mixture & $\begin{array}{l}\text { Indentiflow } ® \text { smart meter }(0.01 \mathrm{~L} \\
\text { resolution) and data logger at } 1 \mathrm{~s} \text {. } \\
\text { intervals }\end{array}$ & $\begin{array}{l}\text { Analysis using Identiflow }{ }^{\circledR} \\
\text { software }\end{array}$ & $\begin{array}{l}\text { Kowalski \& Marshallsay } \\
\text { (2005) }\end{array}$ \\
\hline $\begin{array}{l}\text { 1998-2001 WA Water } \\
\text { Corporation Domestic } \\
\text { Water Use study }\end{array}$ & $\begin{array}{l}\text { Perth, WA, } \\
\text { Aust. }\end{array}$ & $\begin{array}{l}120 \text { and } \\
600 \\
\text { surveys }\end{array}$ & $\begin{array}{l}18 \text { months for } \\
\text { single and } 13 \\
\text { months for multi }\end{array}$ & Single and multi & $\begin{array}{l}\text { Smart meters and loggers } \\
\text { (unspecified) }\end{array}$ & $\begin{array}{l}\text { Manual download to PC in- } \\
\text { situ and Trace Wizard }{ }^{\circledR}\end{array}$ & Bouwer (2000) \\
\hline $\begin{array}{l}1998 \text { USA and Canada } \\
\text { residential end use - } \\
\text { AWWA }\end{array}$ & USA/Canada & 1,188 & $\begin{array}{l}2 \times 2 \text { wks summer } \\
\text { and winter }\end{array}$ & Single detached & $\begin{array}{l}\text { Magnetic water meters, Meter } \\
\text { Master 100EL logger, } 10 \mathrm{sec} \text { int. }\end{array}$ & $\begin{array}{l}\text { Manual logger and download } \\
\text { ex-situ and Trace Wizard }{ }^{\circledR}\end{array}$ & Mayer et al. (2004) \\
\hline
\end{tabular}


Table 2. Existing pattern matchings techniques and a rating of their applicability to the present study

\begin{tabular}{|c|c|c|c|c|c|c|}
\hline \multirow[t]{2}{*}{ Technique } & \multirow[t]{2}{*}{ Research fields typically applied } & \multicolumn{4}{|c|}{ Technique rating category } & \multirow[t]{2}{*}{ References } \\
\hline & & $\begin{array}{l}\text { Processing } \\
\text { efficiency }\end{array}$ & $\begin{array}{l}\text { Recognition } \\
\text { accuracy }\end{array}$ & $\begin{array}{l}\text { Self-learning } \\
\text { potential }\end{array}$ & $\begin{array}{l}\text { Overall } \\
\text { applicability }\end{array}$ & \\
\hline Decision tree & $\begin{array}{l}\text { Medical decision making, risk } \\
\text { management, ecological assessments, } \\
\text { water end use studies, many others }\end{array}$ & $* * * * *$ & $* *$ & $*$ & $* * *$ & $\begin{array}{l}\text { Cha et al. (2009), Deng et al. (2011), } \\
\text { Eggers et al. (2012), Yiee \& Baskin } \\
\text { (2011), Yuan \& Shaw (1995) }\end{array}$ \\
\hline $\begin{array}{l}\text { Artificial Neural } \\
\text { Network (ANN) }\end{array}$ & $\begin{array}{l}\text { All pattern recognition problems } \\
\text { including speech, handwriting, } \\
\text { signature, finger print, etc. }\end{array}$ & $* * * *$ & $* *$ & $* *$ & $* *$ & $\begin{array}{l}\text { Da \& Xiurun (2005), Bhadeshia (1999), } \\
\text { Hert et al (1990), Bishop (1995), } \\
\text { Haykin (1999) }\end{array}$ \\
\hline $\begin{array}{l}\text { Dynamic Time } \\
\text { Warping (DTW) }\end{array}$ & $\begin{array}{l}\text { Limited fields including hand writing } \\
\text { recognition, fault detection, or speech } \\
\text { matching. }\end{array}$ & $* * *$ & $* * *$ & $* *$ & $* * *$ & $\begin{array}{l}\text { Myers \& Rabiner (1981), Muller } \\
\text { (2007), Rabiner \& Juang (1993), Sakoe } \\
\text { \& Chiba (1978) }\end{array}$ \\
\hline $\begin{array}{l}\text { Hidden Markov } \\
\text { Model (HMM) }\end{array}$ & $\begin{array}{l}\text { Most effective in hand writing and } \\
\text { speech recognition }\end{array}$ & $* * *$ & $* * * *$ & $* * * *$ & $* * * *$ & $\begin{array}{l}\text { Baum \& Petrie (1966), Starner \& } \\
\text { Pentland (1995), Baum et al (1970), } \\
\text { Ghahramani \& Jordan(1997), Satish \& } \\
\text { Gururaj (2003), Tapia (2004) }\end{array}$ \\
\hline
\end{tabular}


Table 3. Residential end use analysis techniques comparative analysis matrix

\begin{tabular}{|c|c|c|c|c|c|c|c|}
\hline $\begin{array}{l}\text { Technique } \\
\text { examined }\end{array}$ & $\begin{array}{l}\text { Equipment } \\
\text { required }\end{array}$ & $\begin{array}{l}\text { Recognition } \\
\text { analysis } \\
\text { technique(s) }\end{array}$ & $\begin{array}{l}\text { Processing } \\
\text { efficiency }^{1}\end{array}$ & Accuracy $^{2}$ & $\operatorname{Cost}^{3}$ & Feasibility $^{4}$ & Overall $^{5}$ \\
\hline TraceWizard & $\begin{array}{l}\text { Smart meter } \\
\text { and data } \\
\text { logger }\end{array}$ & Decision tree & $* * * *$ & $* *$ & $* *$ & $* * *$ & $* *$ \\
\hline Identiflow & $\begin{array}{l}\text { Smart meter } \\
\text { and data } \\
\text { logger }\end{array}$ & Decision tree & $* * * *$ & $* *$ & $* *$ & $* * *$ & $* *$ \\
\hline
\end{tabular}

\begin{tabular}{|c|c|c|c|c|c|c|c|}
\hline HydroSense & $\begin{array}{l}\text { Smart meter, } \\
\text { data logger } \\
\text { and pressure } \\
\text { sensors }\end{array}$ & HMM & $* * *$ & $* * * * *$ & $*$ & $* *$ & $* * *$ \\
\hline $\begin{array}{l}\text { Proposed } \\
\text { model }\end{array}$ & $\begin{array}{l}\text { Smart meter } \\
\text { and data } \\
\text { logger }\end{array}$ & $\begin{array}{l}\text { HMM + DTW } \\
+ \text { probability }\end{array}$ & $* * *$ & $* * * *$ & $* * *$ & $* * * *$ & $* * * *$ \\
\hline
\end{tabular}

Note: ${ }^{1}$ processing efficiency relates to time required to recognise end use events, ${ }^{2}$ accuracy relates to techniques degree of accuracy in recognising end use events correctly, ${ }^{3} \cos t$ relates to the capital cost for setup and ongoing resources required to analyse data received, ${ }^{4}$ feasibility relates to viability of widespread rollout of technology for automated end use analysis in a region, and ${ }^{5}$ overall relates to the combined overall assessment on the applicability of the technique for widespread viable automated end use analysis of residential water flow data. Rating system: 1 star $\left(^{*}\right)=$ poor; $* *=$ below average; $* * *=$ average; $* * * *=$ good $; * * * *=$ excellent 
Table 4. General characteristics of monitored households (Beal and Stewart, 2012)

\begin{tabular}{|c|c|c|c|c|c|c|c|c|c|c|c|c|}
\hline \multirow{2}{*}{$\begin{array}{l}\text { Household } \\
\text { Demograhics }\end{array}$} & \multicolumn{3}{|c|}{ Gold Coast } & \multicolumn{3}{|c|}{ Brisbane } & \multicolumn{3}{|c|}{ Ipswich } & \multicolumn{3}{|c|}{ Sunshine Coast } \\
\hline & $\begin{array}{l}\text { Winter } \\
2010\end{array}$ & $\begin{array}{l}\text { Summer } \\
2010-11 \\
\end{array}$ & $\begin{array}{l}\text { Winter } \\
2011\end{array}$ & $\begin{array}{l}\text { Winter } \\
2010\end{array}$ & $\begin{array}{l}\text { Summer } \\
2010-11\end{array}$ & $\begin{array}{l}\text { Winter } \\
2011 \\
\end{array}$ & $\begin{array}{l}\text { Winter } \\
2010\end{array}$ & $\begin{array}{l}\text { Summer } \\
2010-11\end{array}$ & $\begin{array}{l}\text { Winter } \\
2011\end{array}$ & $\begin{array}{l}\text { Winter } \\
2010\end{array}$ & $\begin{array}{l}\text { Summer } \\
2010-11 \\
\end{array}$ & $\begin{array}{l}\text { Winter } \\
2011\end{array}$ \\
\hline $\begin{array}{l}\text { No. of } \\
\text { households }\end{array}$ & 87 & 68 & 33 & 61 & 64 & 26 & 37 & 31 & 12 & 67 & 56 & 39 \\
\hline No. of people ${ }^{2}$ & 230 & 192 & 91 & 164 & 182 & 79 & 96 & 81 & 33 & 171 & 131 & 98 \\
\hline $\begin{array}{l}\text { Av. Household } \\
\text { occupancy }\end{array}$ & 2.6 & 3.0 & 3.2 & 2.6 & 2.8 & 3.0 & 2.7 & 2.6 & 2.8 & 2.5 & 2.4 & 2.6 \\
\hline $\begin{array}{l}\% \text { Households } \\
\text { with } \leq 2 \text { people }\end{array}$ & $58 \%$ & $46 \%$ & $42 \%$ & $41 \%$ & $47 \%$ & $42 \%$ & $51 \%$ & $58 \%$ & $50 \%$ & $46 \%$ & $64 \%$ & $59 \%$ \\
\hline $\begin{array}{l}\% \text { Households } \\
\text { pensioners/ } \\
\text { retired }\end{array}$ & $36 \%$ & $37 \%$ & $30 \%$ & $16 \%$ & $17 \%$ & $4 \%$ & $32 \%$ & $32 \%$ & $8 \%$ & $45 \%$ & $50 \%$ & $46 \%$ \\
\hline $\begin{array}{l}\text { Households } \\
\text { with children } \\
(\text { aged } \leq 17)\end{array}$ & $34 \%$ & $46 \%$ & $52 \%$ & $30 \%$ & $38 \%$ & $46 \%$ & $21 \%$ & $23 \%$ & $33 \%$ & $25 \%$ & $23 \%$ & $28 \%$ \\
\hline $\begin{array}{l}\text { Average age of } \\
\text { children (years) }\end{array}$ & 8.8 & 8.4 & 7.7 & 2.7 & 4.6 & 5.7 & 4.4 & 5.9 & 4.8 & 10 & 9.4 & 10.5 \\
\hline $\begin{array}{l}\text { Income bracket } \\
\text { split }^{3} \\
1: 2: 3: 4: 5: 6: 7\end{array}$ & $\begin{array}{c}13: 11: 8: 6: \\
4: 0: 2\end{array}$ & $\begin{array}{c}13: 15: 8: 11: 7 \\
: 4: 4\end{array}$ & $\begin{array}{c}5: 8: 5: 3: \\
3: 3: 3\end{array}$ & $\begin{array}{c}6: 9: 19: 6: \\
7: 2: 3\end{array}$ & $\begin{array}{c}\text { 5:9:18:6: } \\
9: 3: 3\end{array}$ & $\begin{array}{l}1: 3: 10: \\
1: 5: 2: 0\end{array}$ & $\begin{array}{c}8: 6: 8: 5: \\
3: 3: 1\end{array}$ & $\begin{array}{c}6: 6: 7: 3: 3 \\
: 3: 0\end{array}$ & $\begin{array}{c}1: 3: 2: 2: 3 \\
: 0: 0\end{array}$ & $\begin{array}{c}18: 23: 1 \\
4: 5: 0: 4: \\
0\end{array}$ & $\begin{array}{c}14: 22: 9: 2 \\
: 0: 4: 0\end{array}$ & $\begin{array}{c}9: 14: 7: 1: \\
0: 3: 0\end{array}$ \\
\hline $\begin{array}{l}\text { Education level } \\
\text { split }^{4} \\
\text { PS:HS:T:U }\end{array}$ & 1:21: 9:19 & $1: 24: 16: 27$ & $\begin{array}{l}0: 10: \\
9: 14\end{array}$ & $\begin{array}{l}0: 17: \\
10: 23\end{array}$ & $\begin{array}{c}1: 14: 10: 2 \\
4\end{array}$ & $\begin{array}{l}0: 5: \\
5: 15\end{array}$ & $\begin{array}{l}3: 12: \\
12: 9\end{array}$ & $\begin{array}{l}3: 12: \\
10: 6\end{array}$ & $2: 4: 4: 2$ & $\begin{array}{l}4: 14: \\
25: 26\end{array}$ & $\begin{array}{l}4: 10: \\
21: 21\end{array}$ & $\begin{array}{c}4: 7: \\
13: 15\end{array}$ \\
\hline
\end{tabular}

Notes: ${ }^{1}$ data presented are averages, ${ }^{2}$ this is based on known household occupancies at the time of the initial household water audit and also includes any updates to occupancies which were collated in March this year. This does not include any visitors or absent residents. ${ }^{3}$ income categories: $1=\langle \$ 30,000,2=\$ 30,000-\$ 59,000,3=\$ 60,000-\$ 89,999,4=\$ 90,000-\$ 119,999,5=\$ 120,000-\$ 149,999,6=\geq \$ 150,000,7=$ prefer not to respond. ${ }^{4}$ education categories are $\mathrm{PS}=$ primary school, $\mathrm{HS}=$ high school, $\mathrm{T}=$ trade/TAFE, $\mathrm{U}=$ university (includes post graduate). 
Table 5. Data allocation to intelligent model development

\begin{tabular}{ll}
\hline End use category & $\begin{array}{l}\text { Total number of } \\
\text { collected samples }\end{array}$ \\
\hline Shower & 7,265 \\
Faucet & 36,349 \\
Clothes washer & 8,975 \\
Dishwasher & 4,877 \\
Toilet & 15,468 \\
Bathtub & 496 \\
Irrigation & 1,290 \\
Combined event & 2,883 \\
\hline
\end{tabular}


Table 6. HMM probability of the tested events

\begin{tabular}{ll}
\hline End use model & Probability $(\%)$ \\
\hline Faucet & 0.0013 \\
Leak & 0.0001 \\
\hline Dishwasher & 0.1233 \\
\hline Clothes washer & 0.0468 \\
Shower & 0.0158 \\
Toilet & 0.1014 \\
Irrigation & 0.0010 \\
Bathtub & 0.0031 \\
Combined event & 0.0008 \\
\hline
\end{tabular}


Table 7. Event final likelihood when combining HMM with time-of-day function

\begin{tabular}{llll}
\hline End use model & $\begin{array}{l}\text { HMM probability } \\
(\mathrm{A})\end{array}$ & $\begin{array}{l}\text { 2:00-3:00 am event } \\
\text { probability }(\mathrm{B})\end{array}$ & $\begin{array}{l}\text { Final probability } \\
(\mathrm{A}) \times(\mathrm{B})\end{array}$ \\
\hline Faucet & 0.0013 & 0.4223 & $5.5 \times 10^{-4}$ \\
Leak & 0.0001 & 0 & 0 \\
Dishwasher & 0.1233 & 0.1261 & $155.4 \times 10^{-4}$ \\
Clothes washer & 0.0468 & 0.0892 & $41.7 \times 10^{-4}$ \\
Shower & 0.0158 & 0.0196 & $3.1 \times 10^{-4}$ \\
Toilet & 0.1014 & 0.8251 & $836.7 \times 10^{-4}$ \\
Irrigation & 0.0010 & 0 & $0 \times 10^{-4}$ \\
Bathtub & 0.0031 & 0.0251 & $0.8 \times 10^{-4}$ \\
\hline
\end{tabular}


Table 8. Testing accuracy against $20 \%$ reserved data

\begin{tabular}{llllc}
\hline End use model & $\begin{array}{l}\text { Training set } \\
(80 \%)\end{array}$ & $\begin{array}{l}\text { Testing set } \\
(20 \%)\end{array}$ & $\begin{array}{l}\text { Testing accuracy } \\
(\%) \text { In terms of } \\
\text { number of event }\end{array}$ & $\begin{array}{l}\text { Testing accuracy } \\
(\%) \text { in terms of } \\
\text { volume }\end{array}$ \\
\hline Faucet & 5812 & 1453 & 72.9 & 73.4 \\
Dishwasher & 7180 & 1795 & 84.4 & 81.8 \\
Clothes washer & 3901 & 975 & 85.2 & 74.2 \\
Shower & 12374 & 3094 & 74.5 & 69.6 \\
Full-flush toilet & 15736 & 3934 & 83.8 & 69.7 \\
Half-flush toilet & 7466 & 1867 & 82.6 & 77.3 \\
Irrigation & 1032 & 258 & 73.9 & 54.2 \\
Bathtub & 2306 & 576 & 67.3 & \\
\hline
\end{tabular}


Table 9. Overall end use event matching accuracy comparison

\begin{tabular}{|c|c|c|c|c|c|c|c|}
\hline \multirow[b]{2}{*}{ End use model } & \multirow[b]{2}{*}{$\begin{array}{l}\text { Basic testing } \\
\text { accuracy }(\%)^{1}\end{array}$} & \multicolumn{2}{|c|}{ Home 1} & \multicolumn{2}{|c|}{ Home 2} & \multicolumn{2}{|c|}{ Home 3} \\
\hline & & $\begin{array}{r}\mathrm{HMM} \\
(\%)\end{array}$ & $\begin{array}{l}\text { Extensive testing } \\
\operatorname{accuracy}^{2}(\%)\end{array}$ & $\begin{array}{r}\mathrm{HMM} \\
(\%)\end{array}$ & $\begin{array}{r}\text { Extensive } \\
\text { testing accuracy } \\
(\%)\end{array}$ & $\begin{array}{r}\mathrm{HMM} \\
(\%)\end{array}$ & $\begin{array}{r}\text { Extensive } \\
\text { testing accuracy } \\
(\%)\end{array}$ \\
\hline Tap & 72.9 & 74.3 & 83.2 & 82.6 & 95.9 & 73.3 & 80.1 \\
\hline Dishwasher & 84.4 & 86.6 & 92.1 & 83.2 & 86.5 & 87.1 & 96.5 \\
\hline Clothes washer & 85.2 & 86.2 & 91.9 & 82.1 & 86.3 & 86.6 & 93.2 \\
\hline Shower & 74.5 & 76.1 & 84.8 & 82.4 & 94.8 & 84.3 & 94.5 \\
\hline Toilet & 82.6 & 71.3 & 78.9 & 73.5 & 80.0 & 80.1 & 90.3 \\
\hline
\end{tabular}

\section{Notes:}

1. Basic testing accuracy: HMM average testing accuracy on $20 \%$ reserved data

2. Extensive testing accuracy: The combination of both HMM and proposed additional process

3. Not applied in household. 
Table 10 Accuracy comparison between the developed method and existing water flow trace analysis tool

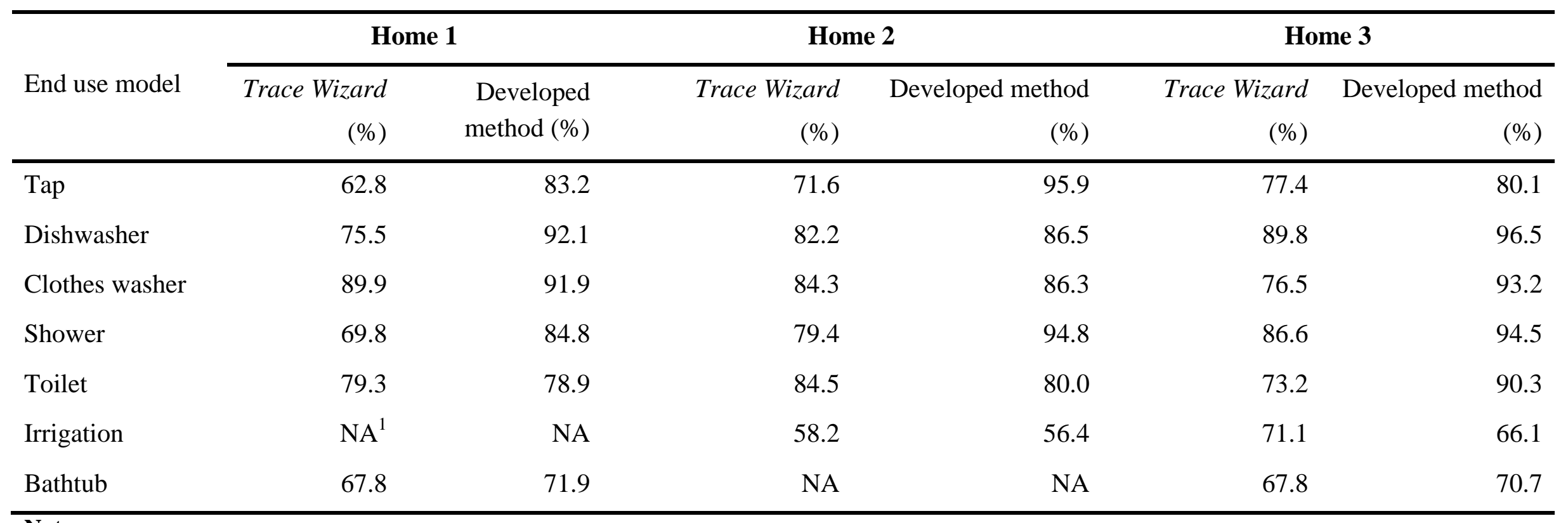

Notes:

1. Not applied in household. 
Table 11 Time-of-day probability distribution

\begin{tabular}{|c|c|c|c|c|c|c|c|c|c|c|c|c|c|c|c|c|c|c|c|c|c|c|c|c|}
\hline Time (24 hr) & $0-1$ & $1-2$ & $2-3$ & $3-4$ & $4-5$ & $5-6$ & $6-7$ & $7-8$ & $8-9$ & $9-10$ & $\begin{array}{l}10- \\
11\end{array}$ & $\begin{array}{l}11- \\
12\end{array}$ & $\begin{array}{l}12- \\
13\end{array}$ & $\begin{array}{l}13- \\
14\end{array}$ & $\begin{array}{l}14- \\
15\end{array}$ & $\begin{array}{l}15- \\
16\end{array}$ & $\begin{array}{c}16- \\
17\end{array}$ & $\begin{array}{l}17- \\
18\end{array}$ & $\begin{array}{c}18- \\
19\end{array}$ & $\begin{array}{l}19- \\
20\end{array}$ & $\begin{array}{c}22- \\
21\end{array}$ & $\begin{array}{l}21- \\
22\end{array}$ & $\begin{array}{l}22- \\
23\end{array}$ & $\begin{array}{l}23- \\
24\end{array}$ \\
\hline Shower & 0.39 & 0.10 & 0.02 & 0.02 & 0.49 & 2.06 & 9.10 & 9.35 & 11.24 & 7.72 & 5.19 & 3.97 & 3.28 & 2.42 & 2.77 & 3.22 & 5.30 & 8.35 & 6.46 & 5.56 & 4.28 & 3.22 & 1.81 & 0.39 \\
\hline Tap & 0.79 & 0.60 & 0.42 & 0.39 & 0.78 & 1.37 & 4.35 & 7.55 & 7.59 & 6.32 & 5.07 & 5.03 & 5.05 & 4.79 & 4.44 & 4.51 & 5.40 & 7.64 & 8.64 & 6.29 & 3.80 & 3.11 & 1.48 & 0.79 \\
\hline $\begin{array}{l}\text { Clothes } \\
\text { washer }\end{array}$ & 0.43 & 0.08 & 0.09 & 0.27 & 0.29 & 0.89 & 3.34 & 7.81 & 11.10 & 12.88 & 10.99 & 8.02 & 6.59 & 5.57 & 4.28 & 4.71 & 5.03 & 4.34 & 4.06 & 3.86 & 1.28 & 1.04 & 0.61 & 0.43 \\
\hline Dishwasher & 1.01 & 0.61 & 0.13 & 0.00 & 0.40 & 0.28 & 2.60 & 4.56 & 6.46 & 6.91 & 5.09 & 3.66 & 4.16 & 4.44 & 4.41 & 3.40 & 3.08 & 5.02 & 9.61 & 12.61 & 6.46 & 4.62 & 1.56 & 1.01 \\
\hline Toilet & 1.28 & 1.11 & 0.83 & 0.69 & 1.38 & 2.35 & 5.53 & 7.96 & 6.91 & 5.69 & 4.72 & 4.27 & 4.21 & 4.35 & 4.40 & 4.78 & 5.35 & 6.03 & 6.00 & 5.82 & 4.74 & 4.13 & 2.47 & 1.28 \\
\hline Bathtub & 1.28 & 1.11 & 0.83 & 0.69 & 1.38 & 2.35 & 5.53 & 7.96 & 6.91 & 5.69 & 4.72 & 4.27 & 4.21 & 4.35 & 4.40 & 4.78 & 5.35 & 6.03 & 6.00 & 5.82 & 0.13 & 0.11 & 0.03 & 1.28 \\
\hline Irrigation & 0.00 & 0.00 & 0.00 & 0.00 & 0.00 & 0.00 & 2.85 & 2.44 & 4.07 & 2.03 & 1.63 & 2.85 & 2.22 & 3.66 & 4.07 & 5.22 & 12.54 & 20.29 & 21.00 & 10.32 & 4.51 & 0.00 & 0.00 & 0.00 \\
\hline Leak & 0.15 & 0.15 & 0.00 & 0.15 & 0.00 & 0.00 & 1.34 & 4.16 & 4.16 & 4.46 & 6.09 & 9.36 & 10.40 & 7.58 & 11.00 & 16.64 & 11.29 & 6.09 & 2.23 & 1.78 & 1.04 & 1.19 & 0.30 & 0.15 \\
\hline
\end{tabular}


Figures

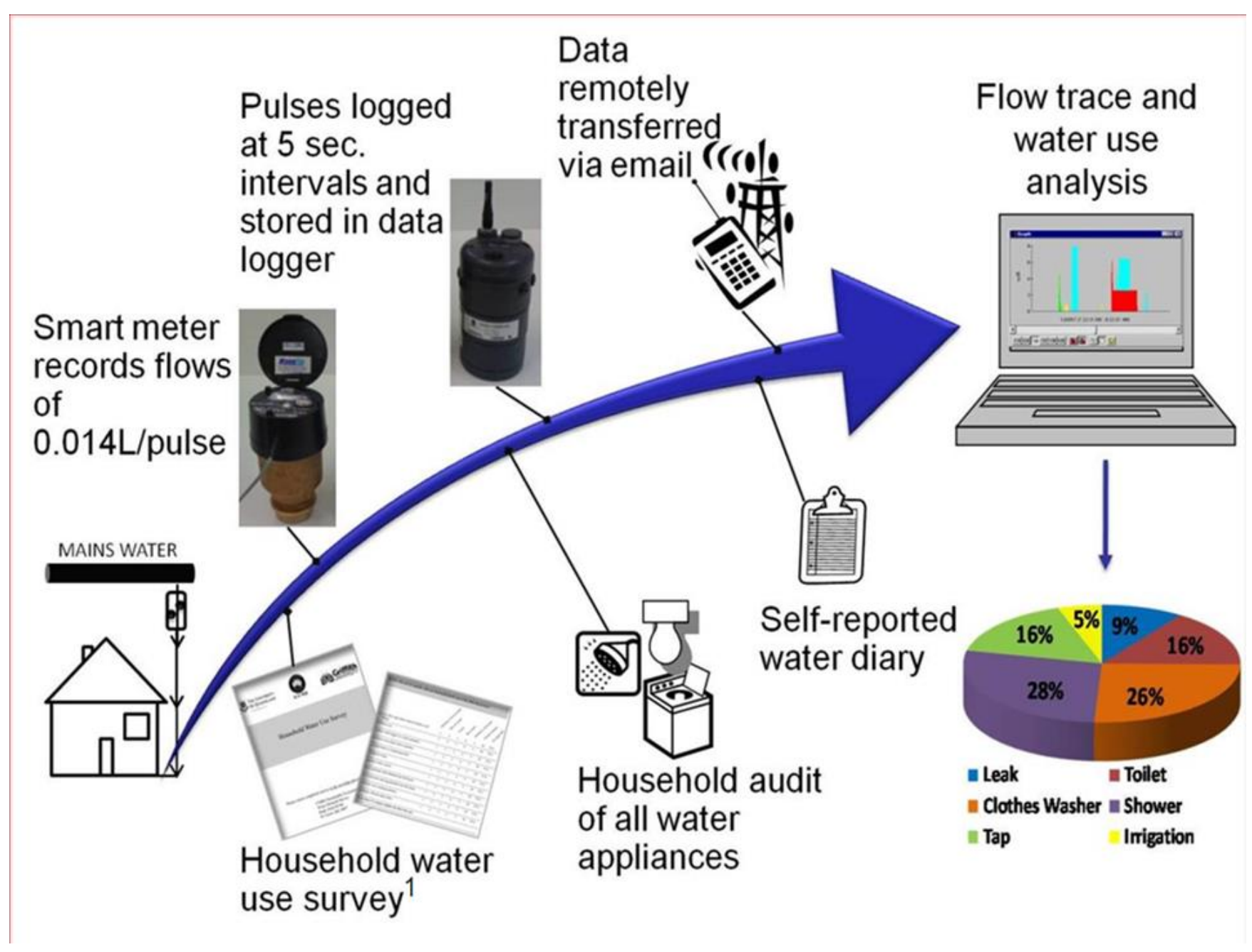

Figure 1 Schematic illustrating water end use analysis process 


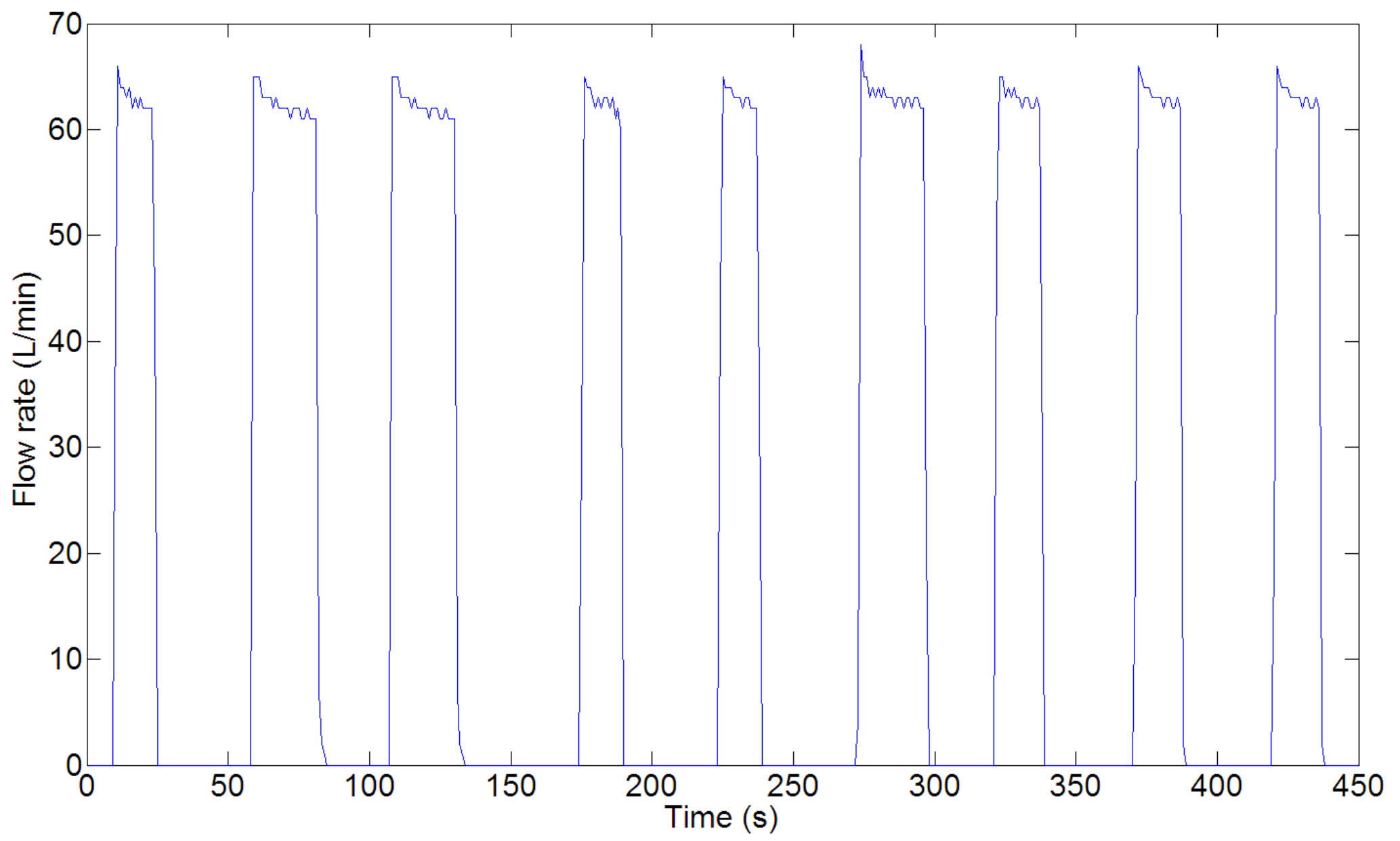

Figure 2 Flow rate pattern of clothes washer events 


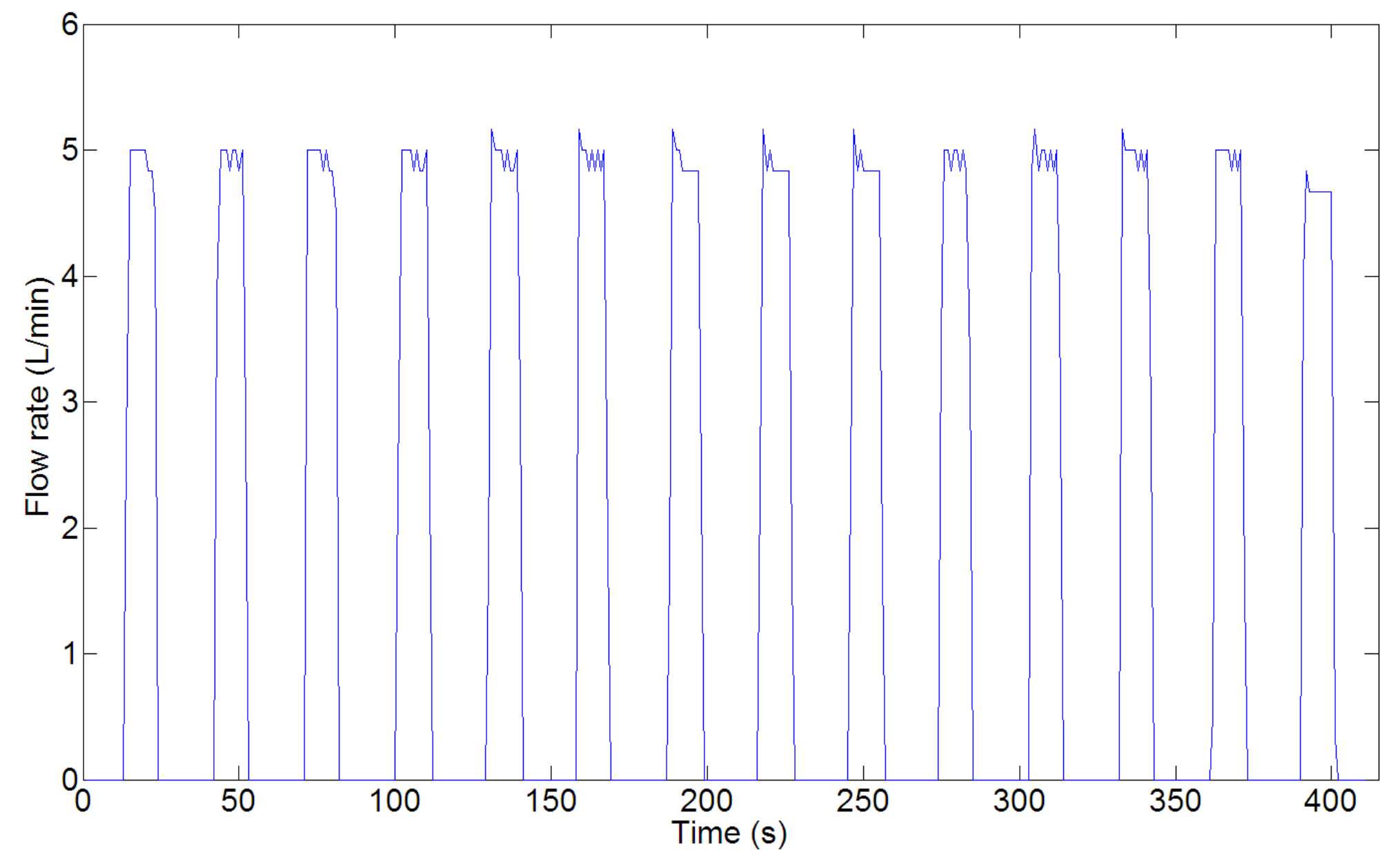

Figure 3 Flow rate pattern of dishwasher events 


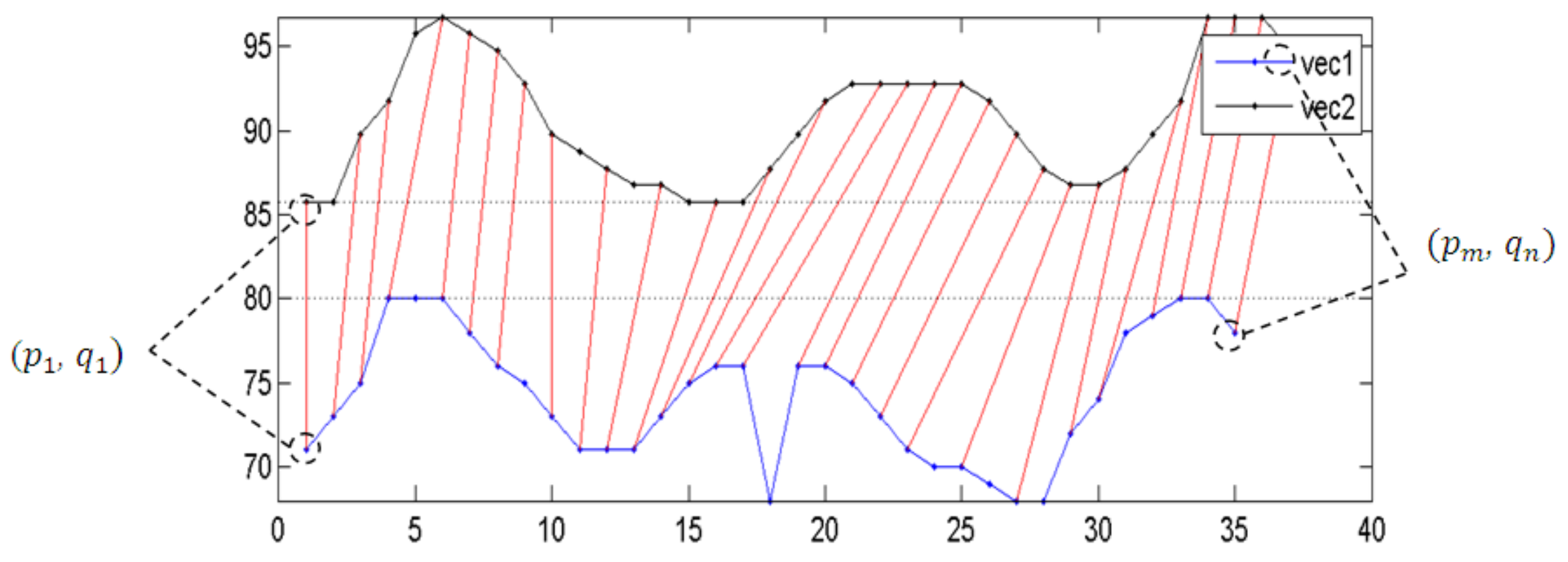

Figure 4 Boundary condition for the two end points in DTW path mapping 


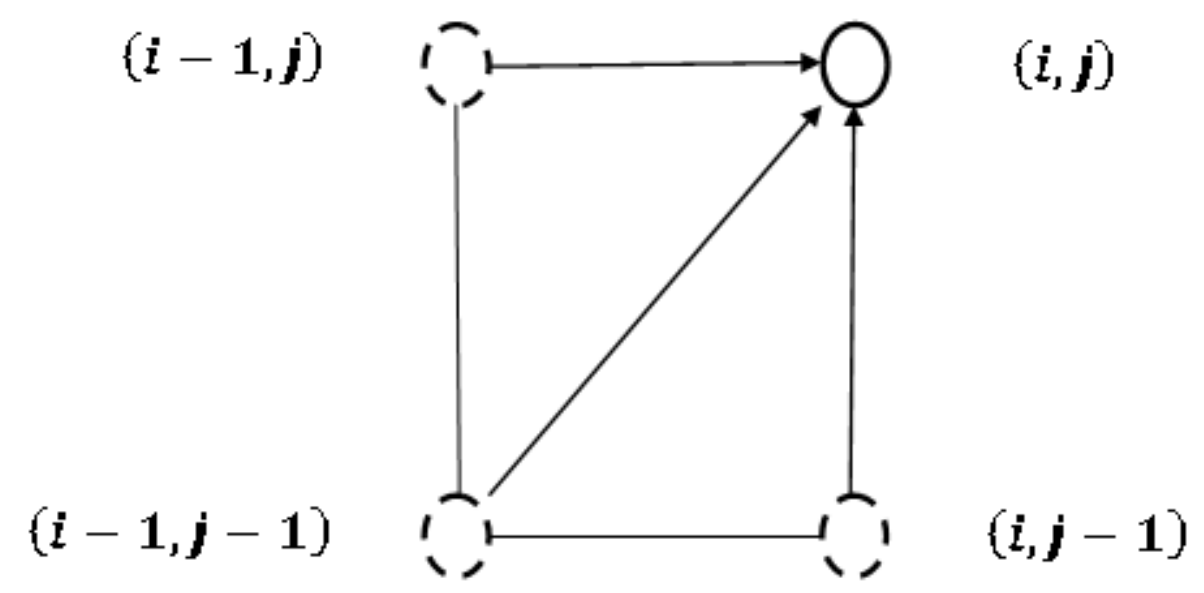

Figure 5 Local constraint for DTW path mapping

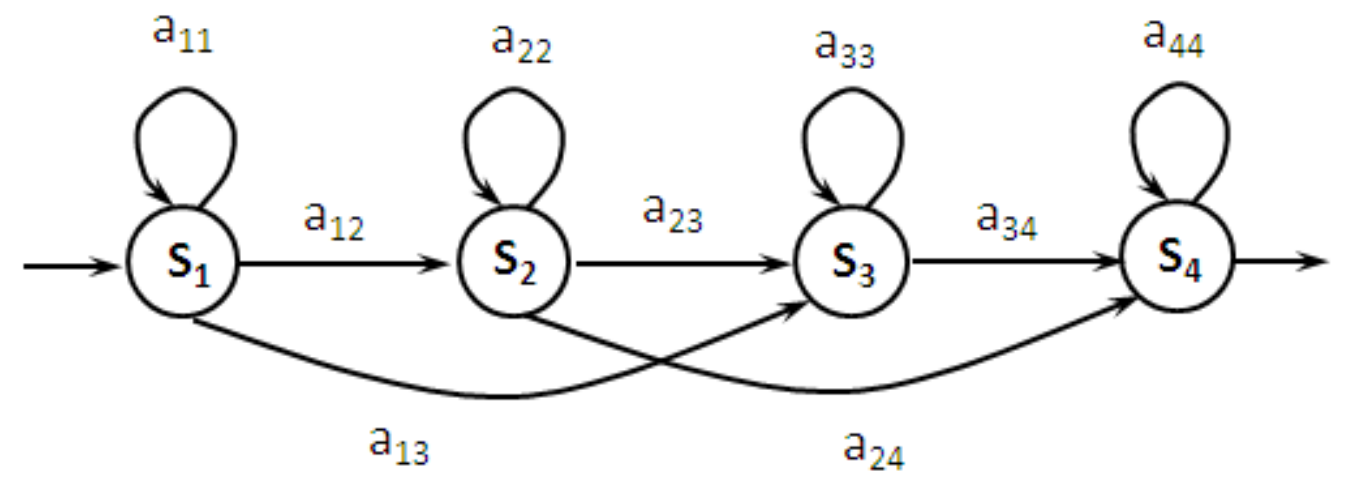

Figure 6 A typical left-right HMM model (i.e. $\mathrm{a}_{12}$ is the transition probability from state 1 to $2, \pi_{1}$ is the probability of being in state 1 at time 1 and $b_{1}\left(o_{1}\right)$ is the probability that observation $o_{1}$ is generated in state 1$)$ 


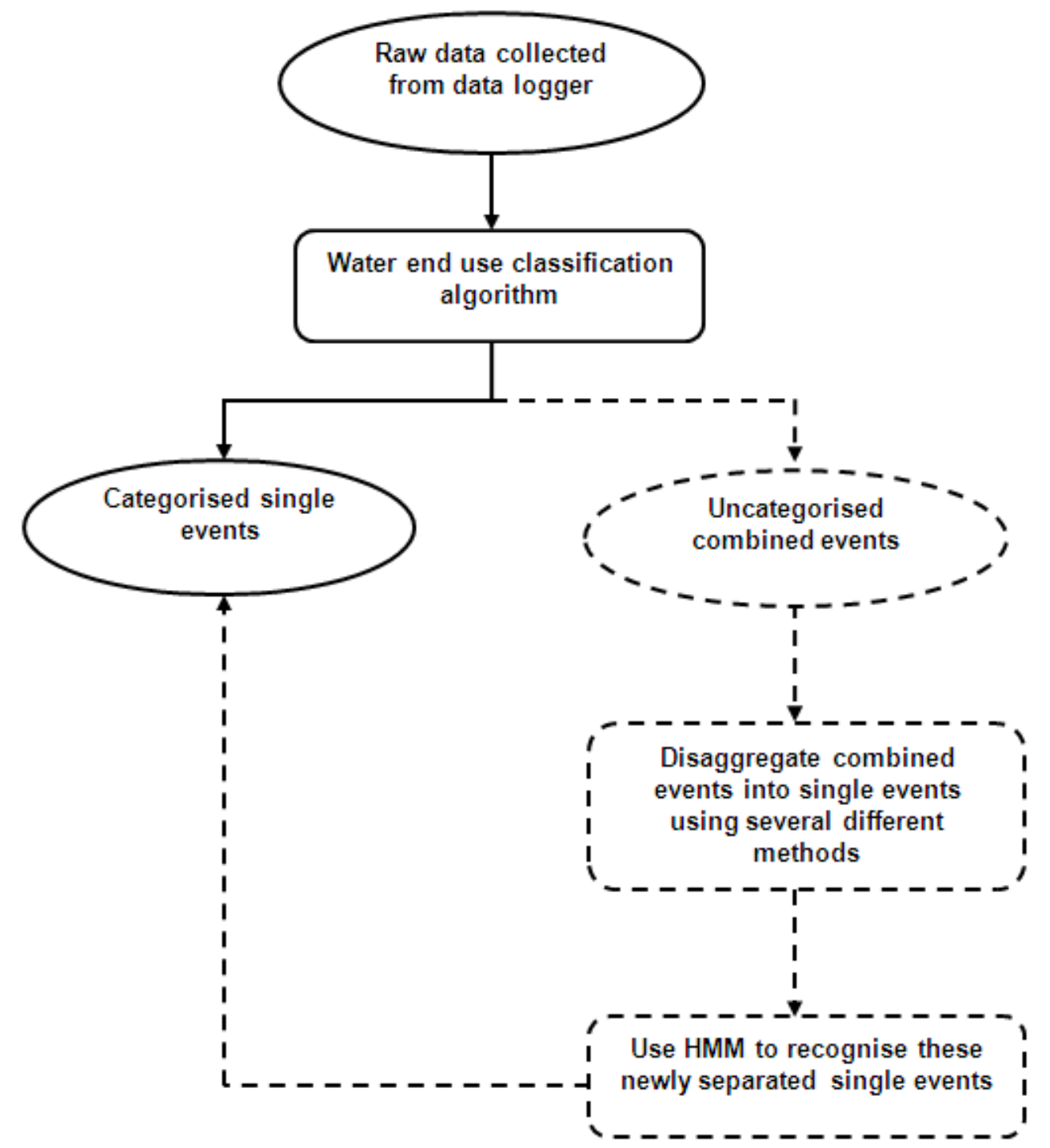

Figure 7 Entire end use categorising process flow chart for both single and combined events 


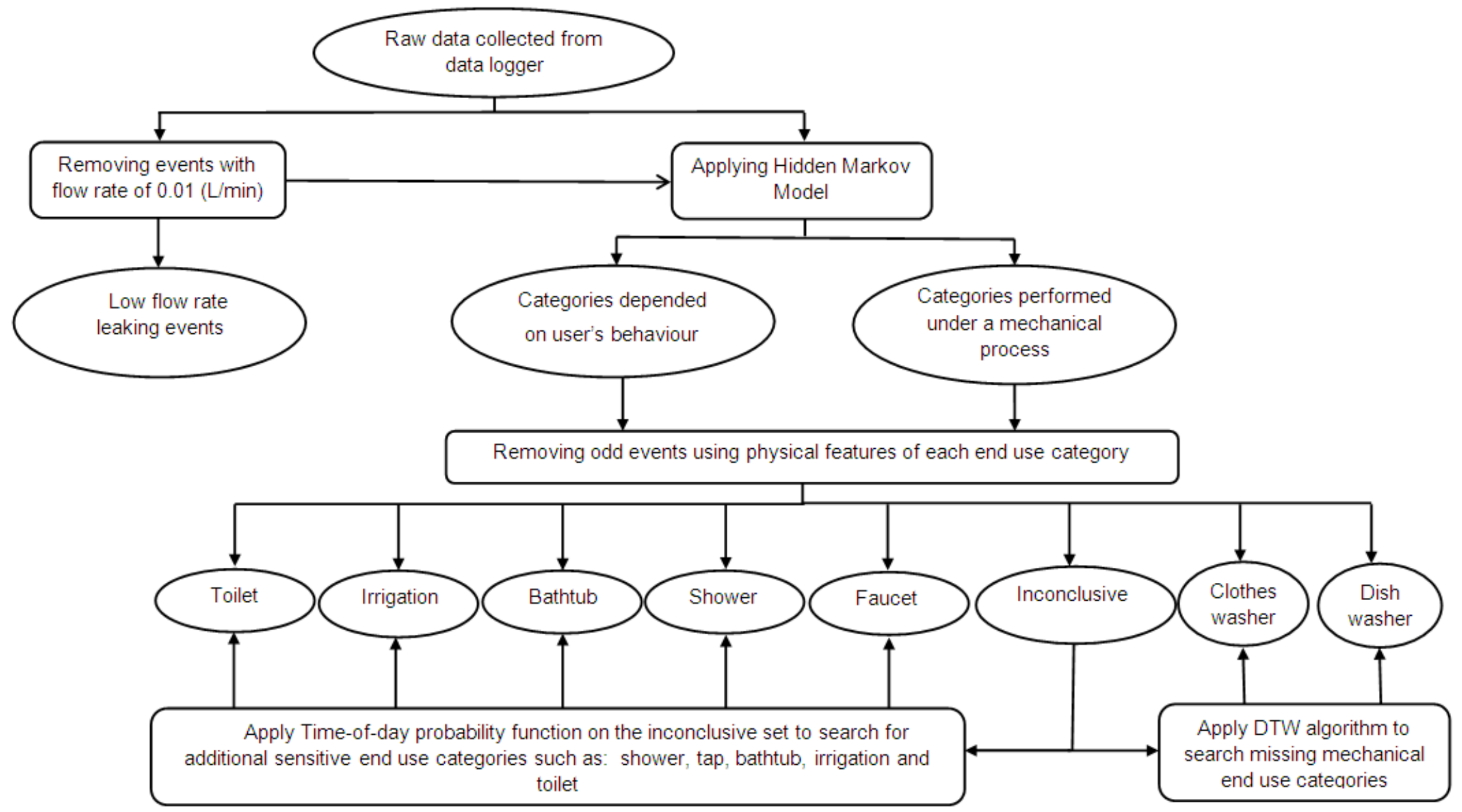

Figure 8 Intelligent model structure for single event categorisation 


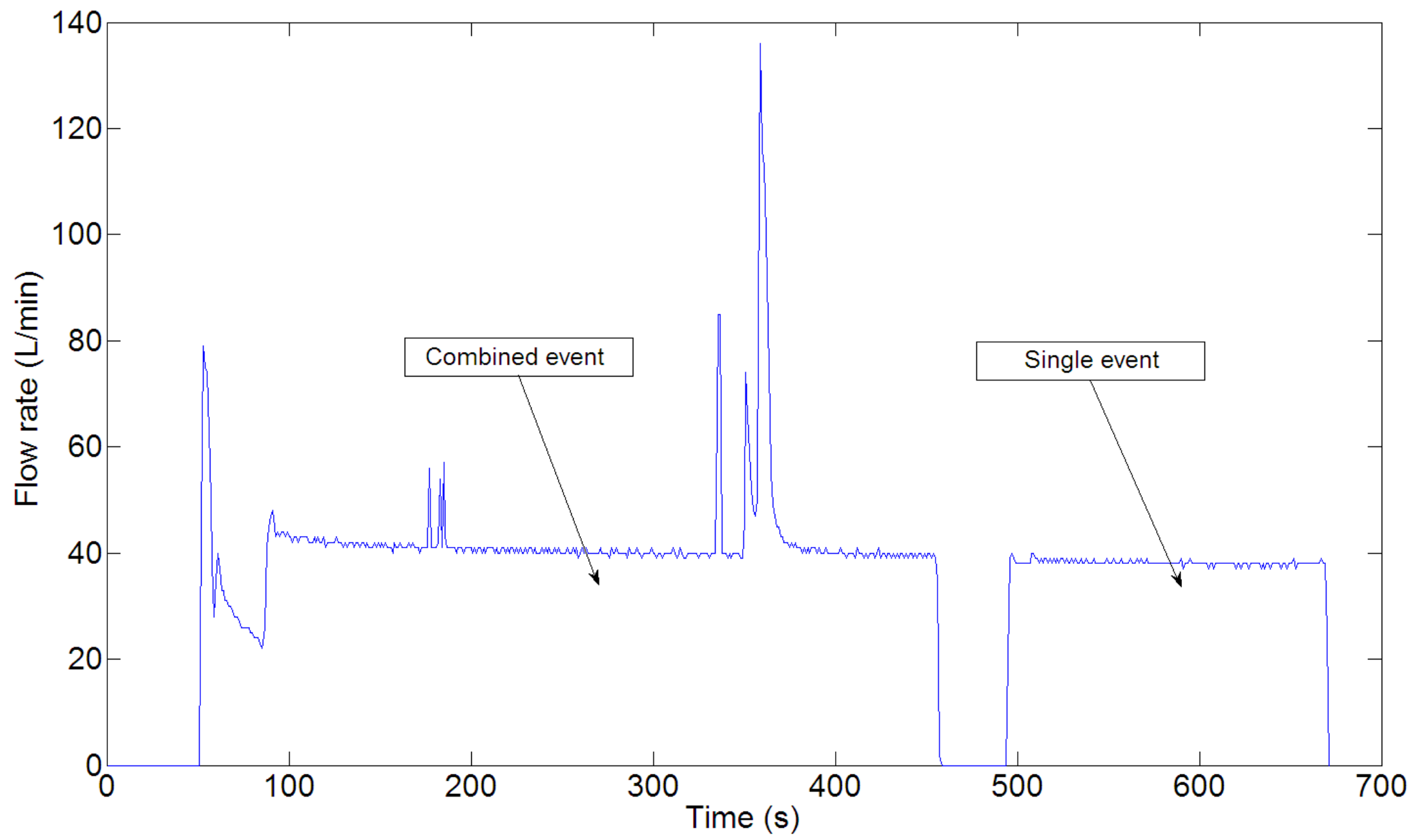

Figure 9 Example of flow rate characteristics for single and combined events 


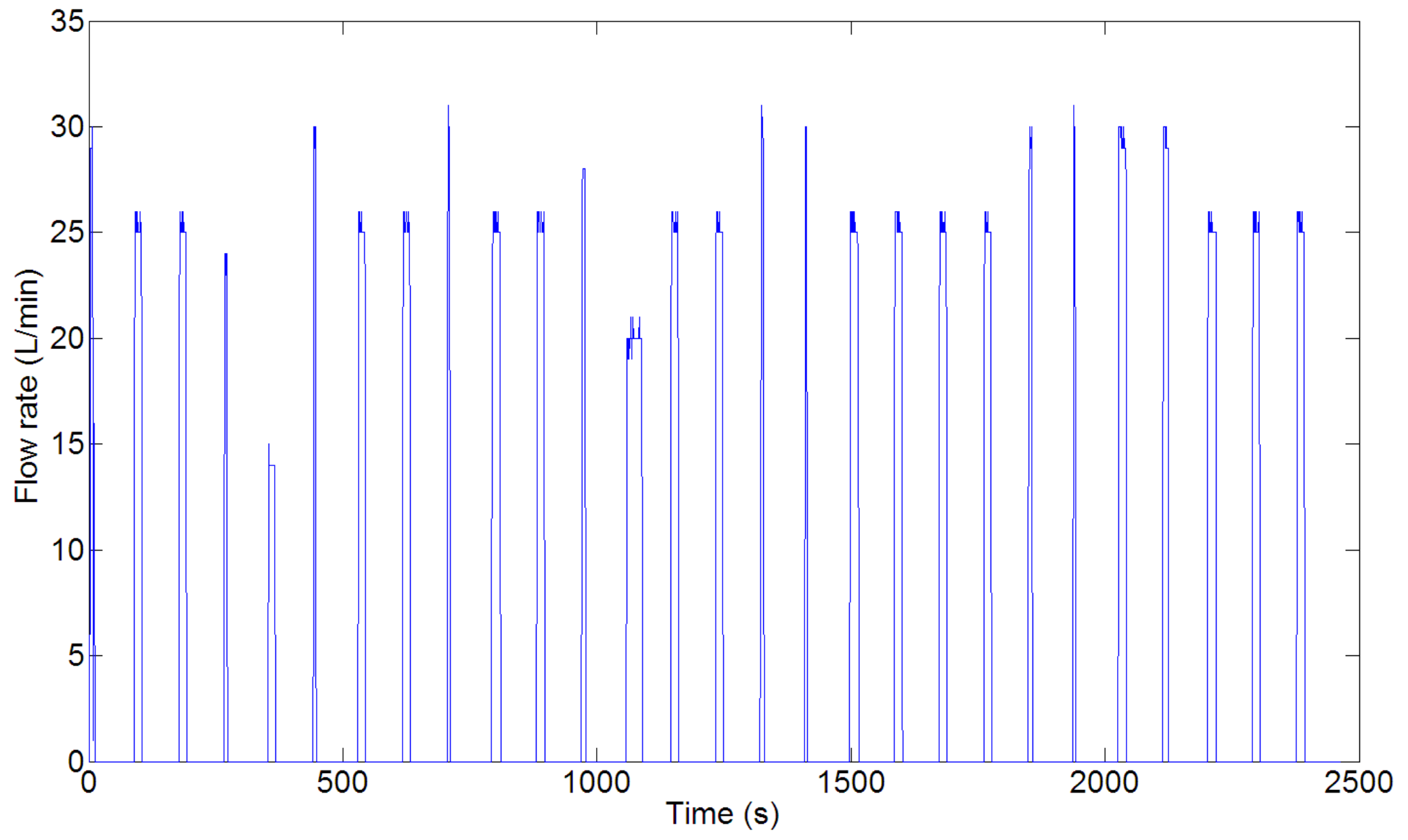

Figure 10 Dishwasher events categorised using HMM method 


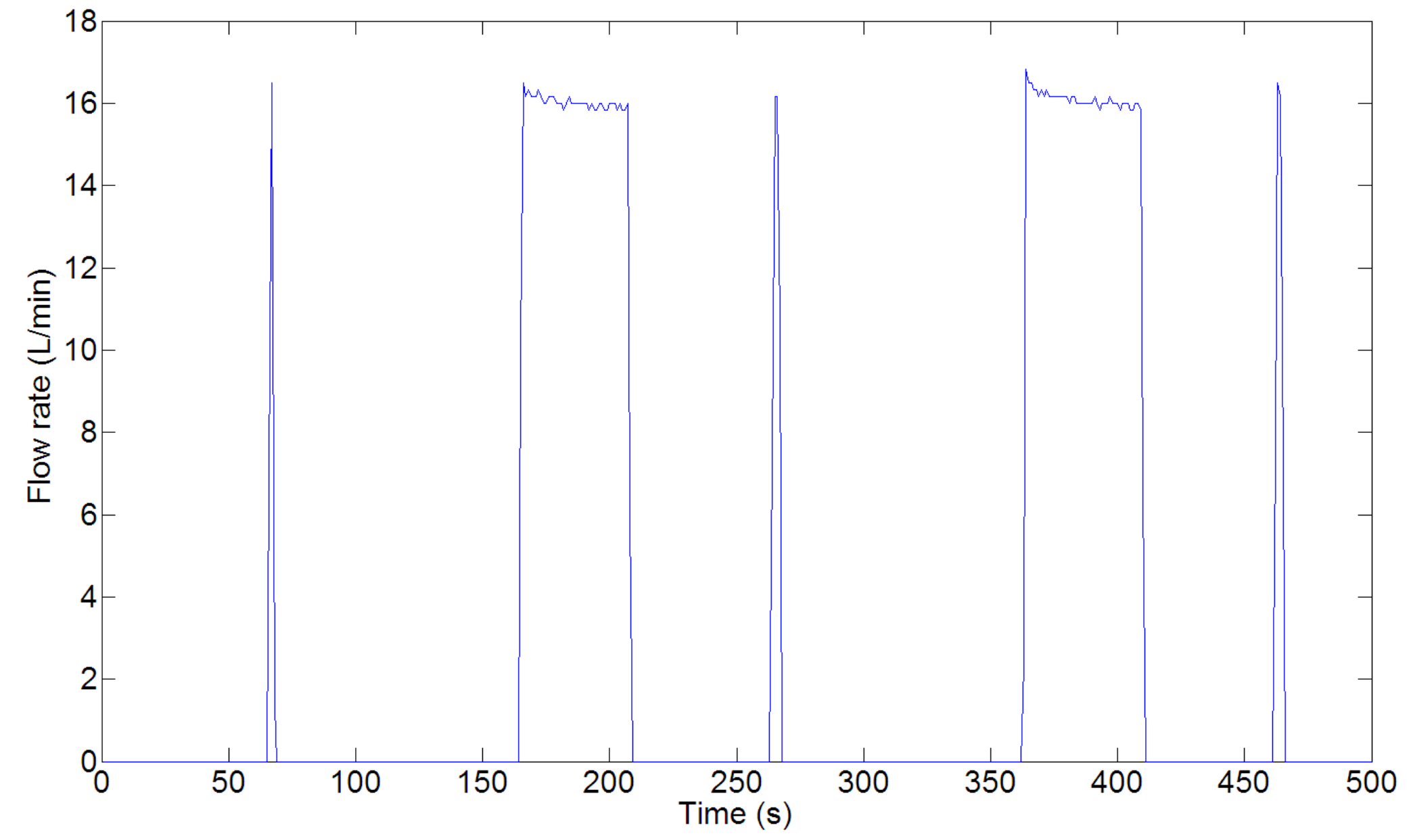

Figure 11 Flow rate pattern of a full clothes washer operation with 5 cycles 


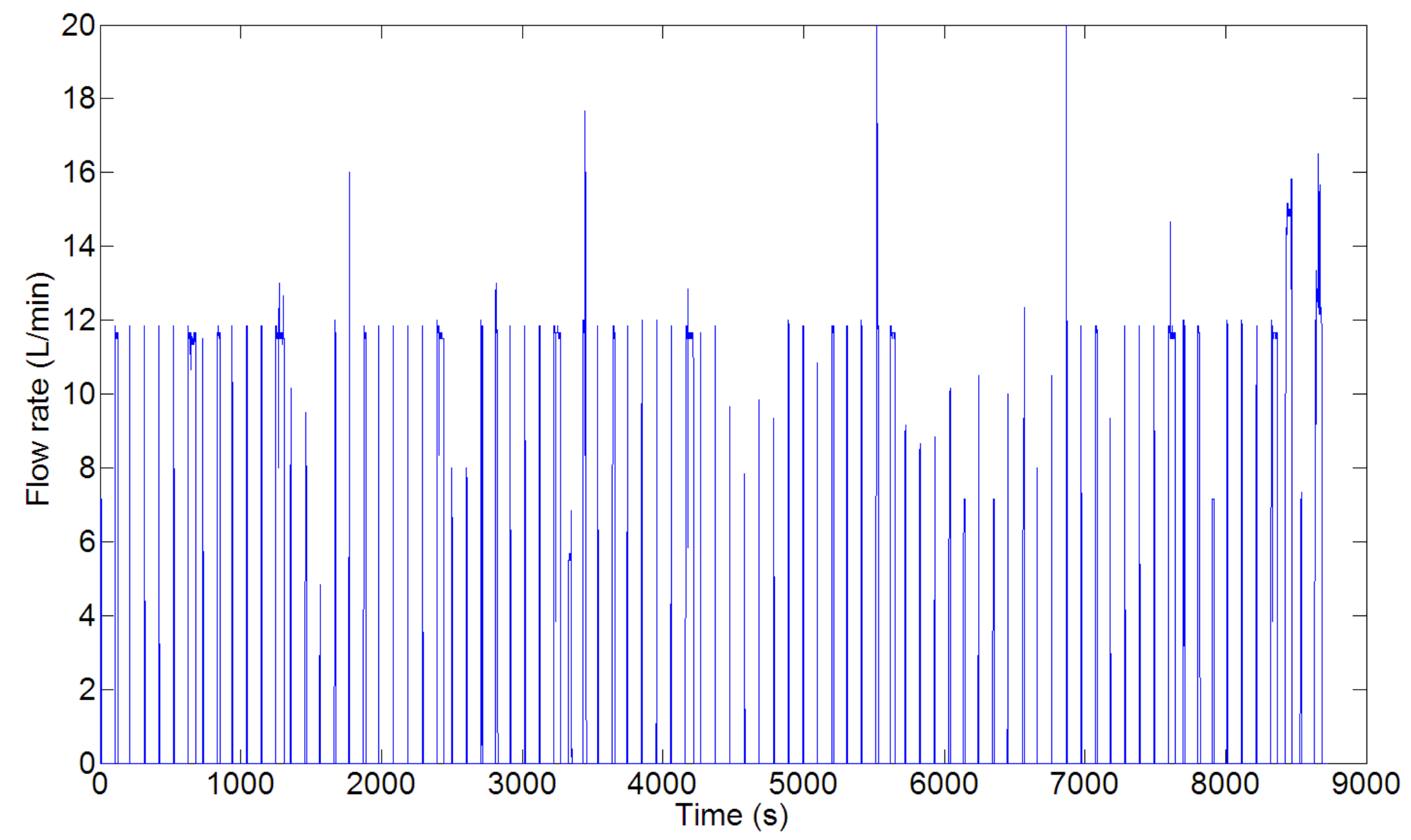

Figure 12 Clothes washer events categorised from preliminary analysis using HMM 


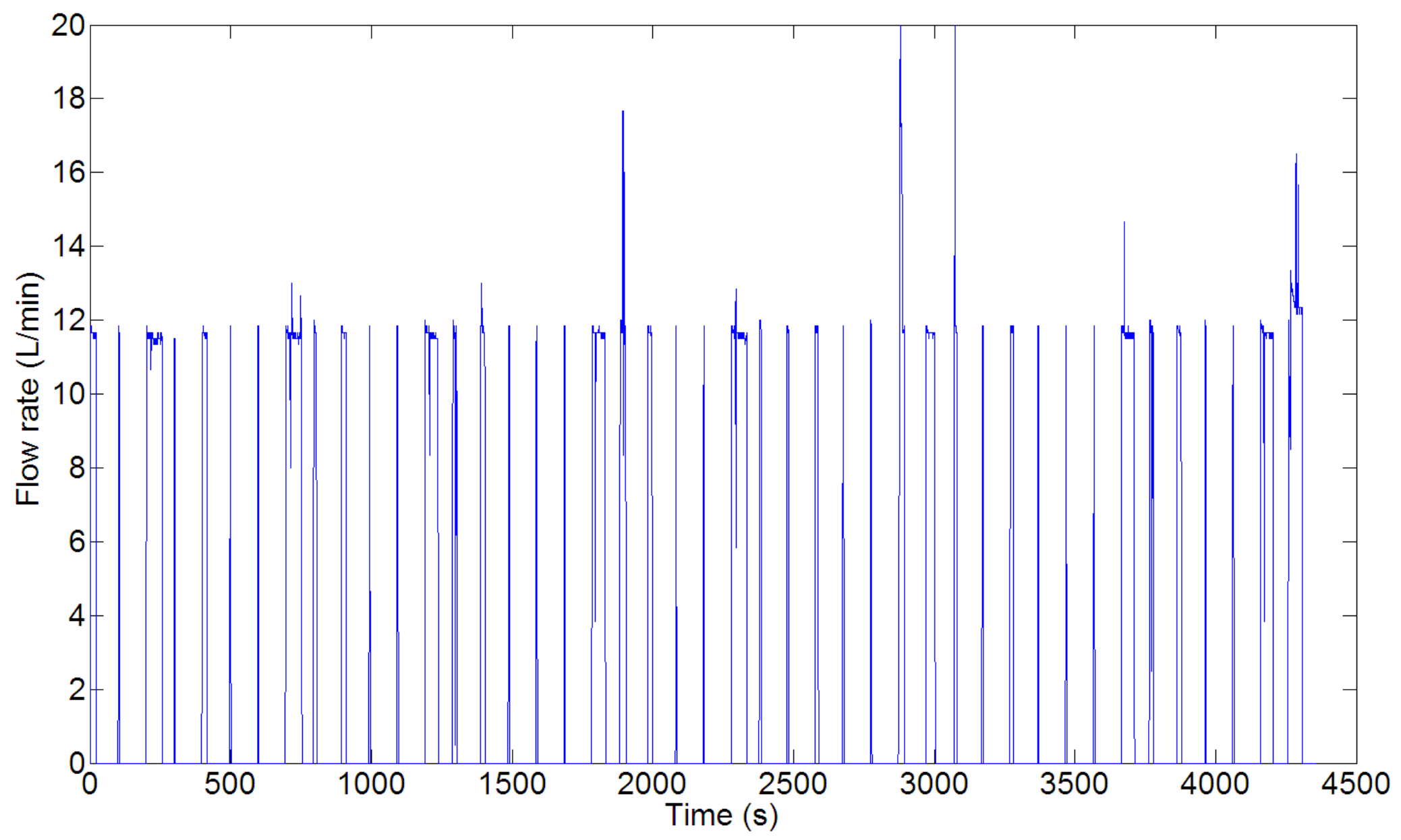

Figure 13 Categorised clothes washer events after refining process 


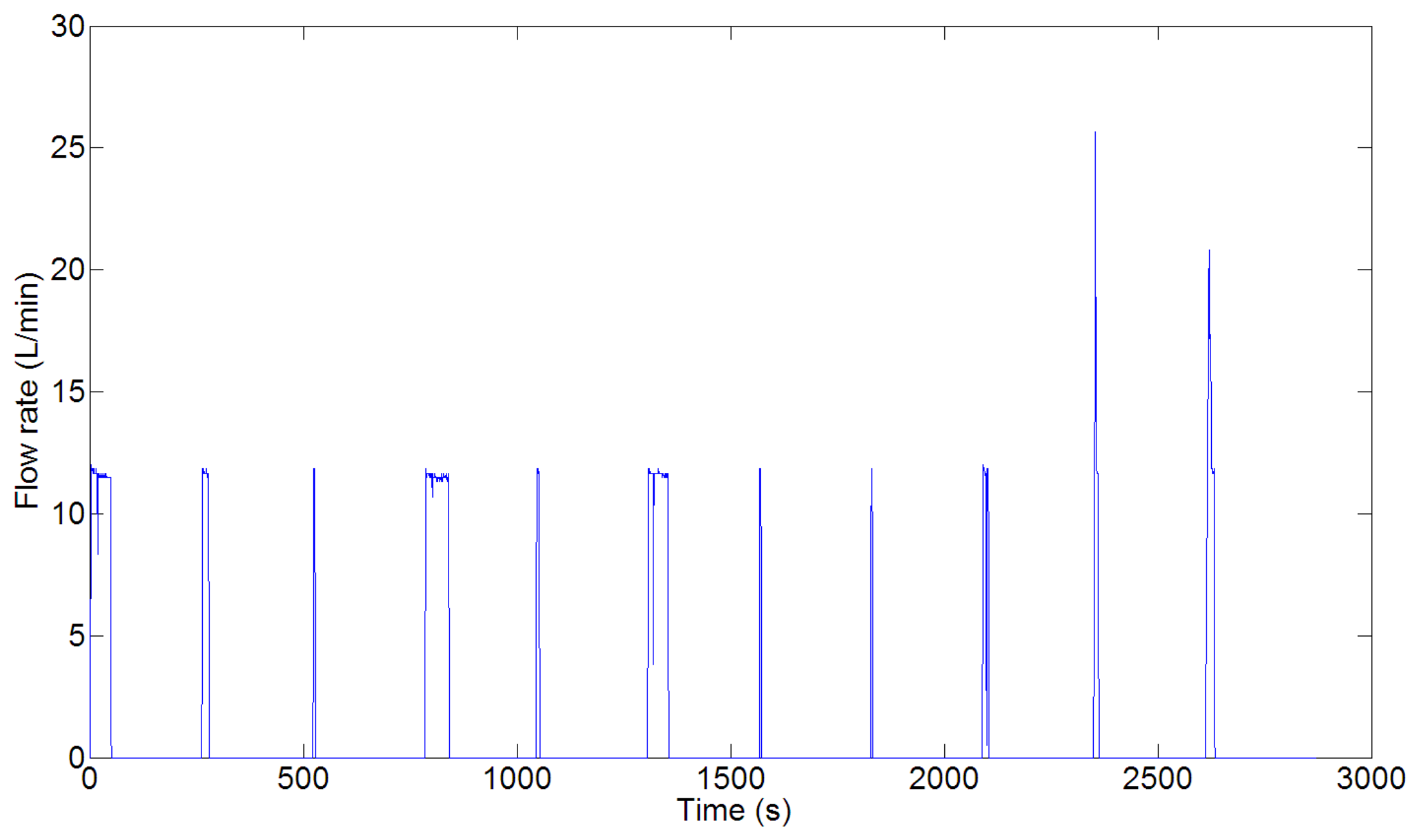

Figure 14 Prototypes of clothes washer events 